\title{
Quantitative mechanical assessment of the whole prostate gland ex vivo using dynamic instrumented palpation
}

${ }^{1}$ SJ Hammer, ${ }^{2,3} \mathrm{D}$ W Good, ${ }^{1} \mathrm{P}$ Scanlan, ${ }^{1} \mathrm{~J}$ Palacio-Torralba ${ }^{2,3} \mathrm{~S}$ Phipps, ${ }^{3} \mathrm{G}$ D Stewart, ${ }^{1} \mathrm{~W}$ Shu, ${ }^{1} \mathrm{Y}$ Chen, ${ }^{2,3} \mathrm{~S}$ A McNeill, ${ }^{1} \mathrm{RL}$ Reuben

${ }^{1}$ Institute for Mechanical, Process and Energy Engineering, School of Engineering and Physical Sciences, Heriot Watt University, Edinburgh, UK.

${ }^{2}$ Dept. of Urology, Western General Hospital, Edinburgh UK

${ }^{3}$ Edinburgh Urological Cancer Group, Institute of Genetics and Molecular Medicine, University of Edinburgh, UK.

\section{Abstract}

An instrumented palpation sensor, designed for measuring the dynamic modulus of tissue in vivo, has been developed and trialled on ex vivo whole prostate glands. The sensor consists of a flexible membrane sensor/actuator with an embedded strain gauge and is actuated using a dynamically varying airflow at frequencies of 1 and $5 \mathrm{~Hz}$. The device was calibrated using an indentation stiffness measurement rig and gelatine samples with a range of static modulus similar to that reported in the literature for prostate tissue. The glands were removed from patients with diagnosed prostate cancer scheduled for radical prostatectomy and the stiffness was measured within 30 minutes of surgical removal. Each prostate was later examined histologically in a column immediately below each indentation point and graded into one of four groups; normal, BPH, cancerous, and mixed cancer and $\mathrm{BPH}$. Eleven prostates were assessed using multiple point probing and the complex modulus at $1 \mathrm{~Hz}$ and $5 \mathrm{~Hz}$ was calculated on a point-by-point basis. The device yielded values of quasistatic modulus of $15 \pm 0.5 \mathrm{kPa}$ and dynamic modulus of $20 \pm 0.5 \mathrm{kPa}$ for whole prostates and a sensitivity of up to $80 \%$ with slightly lower specificity was achieved on diagnosis of prostate cancer using a combination of mechanical measures. This assessment did not take into account some obvious factors such as edge effects, overlap and clinical significance of the cancer, all of which would improve performance. The device, as currently configured, is immediately deployable in vivo. A number of improvements are also identified which could improve the sensitivity and specificity in future embodiments of the probe.

Keywords: prostate, palpation, dynamic stiffness, tissue assessment, trans-rectal sensor

\section{Introduction}

Prostate cancer ( $\mathrm{PCa}$ ) is the most common type of cancer affecting men (1). Early diagnosis of PCa is critical in the management of its treatment and particular recent attention has focused on distinguishing between indolent and aggressive cancers, which may involve monitoring using several 
modes over a period of months or years. Current methods of diagnosis of PCa include; digital rectal examination (DRE), a prostate-specific antigen (PSA) blood test (2), prostate biopsy, trans-rectal ultrasonography (TRUS) (3), trans-rectal sonoelastography (TRSE) (4) and MRI (5). DRE is currently used widely for diagnosis and screening of PCa and the current work is aimed at enhancing the reproducibility and quantification of the finding of a DRE by instrumenting it (iDRE). In conventional DRE, a lubricated and gloved finger is inserted into the rectum and the posterior surface of the prostate is palpated to identify any compliance anomalies which may indicate the presence of PCa (which essentially results in lack of differentiation of the cells, thus altering the mechanical properties). The prostate can also be affected by benign prostatic hyperplasia (BPH) (a proliferation of the glandular component of the prostate leading to enlargement and internal pressure), a condition which is also known to affect its mechanical properties. Because of its subjectivity, it is difficult to use DRE to provide any monitoring, which would require comparison of assessments made over a period of time, perhaps even by different practitioners. However, its ease of deployment and relatively low invasiveness make it an ideal candidate for regular monitoring with an immediate result.

Elevated levels of PSA in a blood test may indicate the presence of PCa but suffers from a high rate of false positives, which may lead to overdiagnosis and overtreatment (6). In a prostate biopsy, several core samples are removed from the prostate using a hollow needle. The microstructure of the core tissue is examined microscopically and any disease present is evaluated using the Gleason severity grade $(7,8)$. The disadvantage of biopsy is that, even when guided using ultrasound or other imaging technique, the needles may miss the affected tissue entirely, especially when any cancerous lesions present are small. Prostate biopsy is invasive and can lead to complications and there is some motivation to provide better pre-biopsy information than is currently available. TRUS and TRSE involve ultrasound waves being directed into the prostate via a trans-rectal transducer/sensor giving a map related to the stiffness of the prostate. In sonoelastography, an external compression is additionally applied to the prostate through the rectal wall using a fluid-filled cover attached to the probe, with images being captured in the compressed and uncompressed states to produce a relative stiffness map $(9,10)$. Shear-wave sonoelastography is a developing technique which uses a compressive acoustic pulse and beam correlation techniques to track the motion of shear waves through tissue (11). Several commercially available clinical ultrasound scanners are available with these ultrasonic techniques although their chief disadvantage is that some types of prostate disease cannot be reliably distinguished due to stiffness artefacts (12). Another image-based stiffness measurement technique is Magnetic Resonance Elastography (MRE) which measures wave field motion through tissue that is induced by an external actuator (13). MRE studies of the prostate have been performed in vivo with actuation either via the urethra $(14,15)$, the rectum $(16)$ or the pubic bone (17) and ex vivo studies (18) on whole prostate glands have also been carried out.

Despite this range of available diagnostic methods and devices, there is an acknowledged clinical need (19) for complementary methods, at least at the early stages. A relatively easily deployable probe providing reliable, reproducible and diagnostically significant information would make a significant difference to the treatment and staging of prostate cancer. The main access point for mechanical assessment of prostate cancer is via the rectum and some devices have already been reported for in vivo trans-rectal use, one example (20) using a balloon inserted trans-rectally and inflated, pressing against the prostate. The shape and texture of the posterior surface was recorded at two different pressures using a camera, the change in volume giving a stiffness map. A number of 
others have already developed point-probe devices and have measured the prostate stiffness ex vivo on prostate slices (21-24) and on prostate chips removed during trans-urethral prostate resection $(25,26)$. Although there is some broad agreement on the absolute values of elastic properties between these studies, it is also clear that there is significant within-patient and between-patient variability and that the test conditions (pre-strain, strain rate and specimen size) all have a significant effect on the values measured (and reported) (27). Nevertheless, there is a strong body of evidence that prostate condition can be assessed mechanically and that, at the very least, contrast between diseased and normal areas can be obtained for a given patient.

In order to tackle patient variability and to use values of elastic modulus for supporting numerical (e.g. FE) modelling, it is necessary to determine the relationship between the tissue structure and its mechanical properties. The tissue structure can be quantified in a number of different ways, perhaps the most useful, in the case of the prostate, being in terms of the histological elements (the glandular acinae with their associated epithelial lining and surrounding stromal tissue) or by the distribution and grade of cancer foci. Earlier attempts at this based on point-probing of prostate slices (27) have indicated that pattern recognition techniques are required even with the heterogeneity exhibited in two-dimensions.

Mechanical measurements on whole prostates are relatively rare. Åstrand et al. (28) have used a tactile sensor equipped with a PZT element to demonstrate contrast between cancerous and noncancerous areas in a single human prostate sample. The method uses changes in resonance frequency of the piezoelectric element as the sensor is pressed against the surface and yields a "stiffness parameter" as opposed to a value of elastic modulus. Although the range of resonance frequency is not mentioned in their paper, it is likely to be in the range of a few tens of $\mathrm{kHz}$, making the stiffness more akin to an ultrasonic (wave propagation) measurement than a mechanical palpation. Most relevant to the current work, Kim et al. (29) have mechanically assessed whole prostates post-laparoscopic prostatectomy using a simulation of the in vivo environment, addressing such issues as the support conditions for the gland, an issue also explored by Palacio-Torralba et al. (30) in an FE model.

The work presented here is ultimately aimed at making an in vivo assessment, devices for which need to be compact and also need to avoid causing harm to the patient or the operator of the device (31). The device whose measurements are reported here is designed for trans-rectal deployment using dynamic instrumented palpation (32) to generate complex modulus measurements over a range of frequencies. In this paper, results of DIP measurements on ex vivo whole prostates are reported to demonstrate the viability of the device for distinguishing tissue quality.

\section{Methods}

\subsection{Patient cohort}

Patients with a diagnosis of localised prostate cancer were invited to participate in the study for the reason that a contrast could be expected between the two lobes. Diagnosis had been confirmed in all patients through the use of biopsy, DRE, PSA testing, multi-parametric MRI and TRUS and the patients were scheduled for radical prostatectomy. Ethical approval was obtained from the local NHS Medical Ethics Committee [Ref: REC (12/SS/1048)] before the study began. The eleven patients 
whose data is presented gave their informed consent to the study. The patients underwent radical prostatectomy (removal of the whole prostate and seminal vesicles) via laparoscopic surgery. The excised whole prostate of each patient was taken from the operating theatre to the laboratory for testing, which was done within 1 hour of removal and took less than 2 hours to complete.

\subsection{Dynamic instrumented palpation (DIP)}

Dynamic instrumented palpation (DIP) involves the measurement of the dynamic stiffness of a material by applying an oscillating displacement and measuring the resulting force or vice versa (32). The dynamic response is often important in distinguishing healthy and diseased tissue, the principle being that it measures time-dependent properties and hence reveals viscous components as well as elastic ones (33). The essential experimental variables in DIP are the frequency of oscillation, the amplitude of the applied force or displacement and the mean value of force or displacement around which oscillation is applied. DIP has been used before to measure the stiffness of prostate chips from trans-urethral prostate resection operations $(25,26)$ and on slices from excised whole prostates (27) using an electromagnetic actuator to deliver an oscillating displacement, a method that is not, of course, deployable in vivo.

The prototype in vivo device used here consists of a flexible silicone membrane that is inflated by pressurised air and has been described elsewhere (34). The device is made up of several laser-cut acrylic layers with engraved channels to allow the entrance of water or air into the membrane chamber. The strain in the membrane from the pressurised fluid is measured using a strain gauge. The membrane consists of two layers of $50 \mu \mathrm{m}$ thick silicone fixed above the membrane chamber using transfer adhesive. The strain gauge is sandwiched between the two layers of membrane to ensure its adhesion to the membrane under dynamic load conditions, and to prevent condensation build up inside the protective sheath used during examinations from causing a short circuit. The membrane is dynamically actuated using a closed air system using an actuator with another driving membrane inside. The driving membrane is actuated using a controlled release of compressed air which causes it to expand, compressing the air inside the closed system and causing the membrane mounted to the device to expand. When the compressed air is exhausted, the driving membrane relaxes and the pressure in the closed system is reduced, leading to the deflation of the device membrane. An image of the probe end of the device used in testing is shown in Error! Reference source not found.. As part of the development of the device the membrane mechanical response was characterised and its time dependent behaviour not found to be significant at the frequencies of interest [35]. The calibration tests, which were carried out before and after use of the device, did not indicate a significant variation in membrane response with repeated cycling.

The pressure behind the membrane in the closed system is measured with a proprietary transducer. In the ex vivo tests, the device is applied to the prostate surface using an XYZ stage which also serves to position the device on the prostates. The applied contact force is measured using a proprietary force sensitive resistor (FSR).

Data from all three sensors were captured as synchronous time series using DAQ hardware mounted in a custom built instrument case, which was connected to a PC running National Instruments LabVIEW. The DAQ hardware was also used to control the solenoid valve, which, in turn, controlled the input of pressurised air into the actuator. A typical actuation waveform and resulting strain gauge waveform are shown in Error! Reference source not found.. 
Typically, data were captured for each probe point at a sampling rate of $1000 \mathrm{~Hz}$ over around 20 seconds and the signals averaged to produce a mean value, a mean amplitude and a phase at the fundamental actuation frequency for each of the strain and pressure. A relative stiffness map for each prostate was calculated based on three characteristics of the strain gauge and flow pressure sensor signals: the mean ratio (MR), amplitude ratio (AR) and the phase difference (PD).

Mean ratio was calculated using

$$
M R=\frac{\bar{P}_{\text {flow }}}{\bar{\varepsilon}}
$$

where $\bar{P}_{\text {flow }}$ is the mean pressure measured by the flow sensor, and $\bar{\varepsilon}$ is the mean strain, related to the displacement of the membrane into the tissue. The mean ratio thus gives a measure of the quasi-static stiffness of the prostate tissue at that point.

Amplitude ratio was calculated using

$$
A R=\frac{\hat{P}_{\text {flow }}}{\hat{\varepsilon}}
$$

where $\hat{P}_{\text {flow }}$ is the amplitude of the pressure measured by the flow sensor and is related to the oscillating force, and $\hat{\varepsilon}$ is the amplitude of the strain, so that AR gives a relative measure of the magnitude of the dynamic stiffness, with the phase difference completing the description of the dynamic response. The contact force (and hence depth of indentation before the membrane is oscillated) does not figure in the calculation of the stiffness map, although it needs to be recorded since both the dynamic and static stiffness can, especially in soft materials, vary significantly with mean stress or strain.

\subsection{Calibration}

In the interest of designing a probe that is deployable with minimum patient discomfort, it was necessary to adopt a "soft" design for the sensor and actuator. Such an approach requires careful calibration to ensure that the static and dynamic properties of the actuator can be de-convolved from the tissue response and also to enable a conversion of stiffness (force per unit displacement) to modulus (stress/strain).

Accordingly, the DIP device was run back-to-back with a calibrated loading frame (Biomomentum Mach-1, www.biomomentum.com) specifically designed for viscoelastic specimens (Error! Reference source not found.), measuring the dynamic and quasi-static stiffness of a range of gelatine samples. The gelatine samples were made with $3 \mathrm{~g}, 4 \mathrm{~g}, 5 \mathrm{~g}, 6 \mathrm{~g}, 7 \mathrm{~g}$ or $8 \mathrm{~g}$ of gelatine powder, dissolved in $40 \mathrm{ml}$ of boiling water and left overnight in a refrigerator at $4^{\circ} \mathrm{C}$ to solidify. On the day of testing, the gel samples were removed from the sample container and applied to the XYZ measurement stage (for DIP device measurement) or the measurement stage found on the Mach-1.

The gelatine samples were chosen to have a range of stiffnesses and applied forces similar to those measured on the prostates. For each indentation, the $6 \mathrm{~mm}$ diameter hemispherical probe tip of the 
Mach-1 was advanced the corresponding depth below the surface of the gelatine sample. Each dynamic actuation used a $0.5 \mathrm{~mm}$ amplitude sinusoidal displacement waveform. This amplitude is $0.2 \mathrm{~mm}$ less than the mean height of the $6 \mathrm{~mm}$ diameter membrane used on the DIP device when it is dynamically inflated (35), but allows the Mach-1 to operate at its maximum actuation frequency of $5 \mathrm{~Hz}$. A reduced range of indentation depths was used for some samples to avoid damage to the gel sample. Actuation frequencies of 1 and $5 \mathrm{~Hz}$ were used on all samples and an extended range was used for the membrane to assess its dynamic performance. The stiffness measurements (in $\mathrm{gf} / \mathrm{mm}$ ) from the Mach-1 were converted into values of elastic modulus, $E$, using the Hertz-Sneddon equation

$$
E=\frac{3}{4} \cdot \frac{\left(1-v^{2}\right) \cdot f_{z}}{\sqrt{R} \cdot \sqrt{\delta_{z}^{3}}}
$$

where $f_{z}$ is the reaction force $(\mathrm{N}), R$ is the radius of the indenter $(\mathrm{mm}), \delta_{z}$ is the indentation depth $(\mathrm{mm})$ and $v$ is Poisson's ratio (taken to be 0.499$)(36,37)$.

Error! Reference source not found. shows that the static modulus increases with gel strength and does not vary significantly with frequency, as expected. The static modulus also increases a little with pre-indentation, suggesting a slightly stiffening stress-strain curve, apart from the initial stage. The dynamic modulus (Error! Reference source not found.) is generally higher than the static modulus and increases more markedly with indentation depth. The change with frequency is again small. The values obtained for the phase difference did not vary in any systematic way with depth, frequency or gel strength and the mean was close to zero in all measurements, although with a scatter of around 1 radian (Figure 6 ), indicating that the calibration material has no measurable phase response at the frequencies used.

The DIP device was pressed onto the gel samples using indentations of between 0 and $5 \mathrm{~mm}$ at 1 $\mathrm{mm}$ intervals covering the range used on the ex vivo prostate specimens. For each gelatine sample, the stiffness measured using the DIP device was plotted against the elastic modulus calculated from the Mach-1 results. A linear fit was applied, yielding calibration equations which could be used to determine the dynamic modulus $\left(E_{\text {dynamic }}\right)$ (Figure 7$)$ and the quasi-static modulus $\left(E_{\text {static }}\right)$ (Figure 8) from the measured force and displacement in the DIP device. For the dynamic modulus (Figure 7), the calibration is quite reliable at $5 \mathrm{~Hz}$, but less so at $1 \mathrm{~Hz}$, where higher gel strengths and deeper preindentation levels (i.e. higher reaction forces) lead to outliers. For the static modulus (Figure 8) the correlation is similarly poor for both frequencies and there is a distinct stratification in terms of gel strength, probably again reflecting non-linear behaviour in the membrane under higher forces. The phase does not require calibration between the two methods of measurements since it is related to time. However, it does reveal the viscous behaviour of the DIP probe against which any phase difference measured on the prostate samples can be set. As with the Mach 1, the phase measured with the DIP device showed no systematic relationship to gel strength or depth of penetration. Plotted against frequency (with the effects of depth and gel strength embedded in the scatter), Figure 9, reveals a tendency for the phase to increase with frequency. The values of phase are considerably larger for the DIP device than they are for the Mach 1. It might be noted that the negative values recorded at $15 \mathrm{~Hz}$ are likely to be due to the $2 \pi$ ambiguity in the processing algorithm. Overall, the calibrations show that amplitude ratio is likely to be more reliable way of 
assessing prostate material using the DIP probe than is a static modulus, since it behaves more reliably under small changes in displacement.

\subsection{Measurement protocol}

Point measurement on excised prostates was carried out using a manual XYZ positioning stage (Error! Reference source not found.10) with a working volume of $100 \times 100 \times 100 \mathrm{~mm}$, large enough to allow probing of the majority of prostates encountered. The DIP device was covered with a sterile sheath and fixed to the stage using a screw clamp, while the prostate rested on the flat surface of the stage with its anterior surface downwards. The stiffness of the prostate was measured at up to 35 locations, spaced around $6 \mathrm{~mm}$ apart, on the posterior surface, the position being recorded using the scales on the XYZ stage. At each probe point, the device was advanced by $3 \mathrm{~mm}$ in the Z-direction after touching the surface and oscillated at $1 \mathrm{~Hz}$ and $5 \mathrm{~Hz}$ for around 10 cycles. The process was repeated for depths of $5 \mathrm{~mm}$ and $8 \mathrm{~mm}$. The pressure and strain were used, as before, to determine mean ratio, amplitude ratio and phase and the corresponding values converted to moduli using the calibration equations described in the previous section.

It should be emphasised that this protocol was somewhat idealised in order to provide a comparison with the calibration measurements and to register the probe points with the histological analysis. Such a protocol could not be reproduced easily in vivo and the implications of support conditions, attitude of the probe relative to the gland, number of probe points and test duration are discussed in Section 4.

\subsection{Histological analysis}

After testing, each prostate was subjected to histological examination to determine the type and distribution of tissue throughout the gland. The positions of the surgical clips seen in Figure 10 were noted on the pathology report after processing according to International Society of Urological Pathology guidelines. The H\&E-stained transverse sections corresponding to the rows where stiffness measurements had been made were imaged using a microscope and classified using image analysis software (Image Pro Premier, Media Cybernetics Inc., http://www.mediacy.com/). Four main tissue classifications were used for each location: 'Normal' (no visible disease of any kind present), 'BPH' (benign prostatic hyperplasia nodules were present), 'Cancer' (a prostate cancer tumour was identified) and 'Mixed' (both prostate cancer and BPH were identified).

Figure 11 shows a typical probing sequence on the posterior surface along with an example of the corresponding transverse histological section. The probe points were set apart by the nominal diameter of the probe and so the entire posterior surface was covered without significant overlap. Each probe point corresponded to a column of diameter $6 \mathrm{~mm}$ and the depth of the prostate and the assessment referred to above applied to the entire column. Probing was carried out at frequencies of $1 \mathrm{~Hz}$ and $5 \mathrm{~Hz}$ and at depths of $3 \mathrm{~mm}$ (Depth A), $5 \mathrm{~mm}$ (Depth B) and $8 \mathrm{~mm}$ (Depth C). As can be seen for the example section shown in Figure 11, the depth of the prostate can vary with position as can

http://mc.manuscriptcentral.com/(site) 
the depth of different histological features, so different depths may reveal different aspects of the mechanical behaviour more clearly.

\section{Results}

\subsection{Data summary from 11 prostates}

Eleven prostate glands were measured ex vivo using a single build of the DIP sensor, whose calibration was described earlier. A total of 359 points were assessed under six conditions (two frequencies and three depths), yielding a mechanical feature vector of between 6 and 18 elements, depending on whether the depth is stratified. The histological classification (4 target) of the positions measured on these samples is shown Table 1 , which also gives a simpler classification in terms of presence or absence of cancer (2 target).

Figure 12 shows boxplots of quasi-static modulus, dynamic modulus and phase difference, classified by histology for the shallowest indentation (Depth A). It is clear that variations of the expected type are present, e.g. that cancer is stiffer than normal or BPH tissue and that it exhibits smaller phase differences. Table 2 shows the values of modulus and phase difference for the 11 patients, classified in two ways, normal tissue vs. cancer (excluding the "mixed" group), and benign (i.e. normal plus $\mathrm{BPH}$ ) vs. malignant (i.e. cancer plus mixed). Besides showing the mean and standard deviation for each mechanical feature, Table 2 also shows the result of a $t$-test between the two classifications, $\mathrm{P}$ values less than 0.05 normally being taken to indicate that the differences between the mean values are statistically significant.

From Figure 12 and Table 2, it is clear that, using one of the three depths and the limited range of frequency studied, only some of the mechanical indicators are able to distinguish cancer from normal tissue over a range of patients and also between benign and malignant conditions. However, there is no obvious explanation as to why some indicators are better than others, requiring a more detailed analysis of patient-specific, location-specific and device-specific effects.

\subsection{In-patient variation (effect of heterogeneity)}

A typical example of the variation in quasi-static modulus, dynamic modulus and phase difference for a single patient is shown alongside the corresponding histology slices in Figure 13. Even with this simplified presentation, it is possible to discern patterns in the mechanical indicators that reveal the presence of the area of cancer, highlighted in dark colour.

Because of the complexity of the mechanical information (six features at three depths) and the heterogeneity of the column, even using the simplified classification, a pattern-recognition tool was used to assess in-patient sensitivity (i.e. proportion of points with disease which return a positive result from the mechanical indicators) and specificity (i.e. proportion of points without disease which return a negative result from the mechanical indicators). A proprietary algorithm (Matlab) consisting of a two-layer feed-forward Artificial Neural Network (ANN) was used, incorporating sigmoid neurons in the hidden layer and "softmax" neurons in the output layer. The mechanical data at each point were input as a feature vector and the target consisted of a two- or four-element vector with zeroes in all but the correct classification (Table 1). 
In each ANN run, 10 iterations of training (using scaled conjugate back-propagation) were used, each time with the data set being divided randomly into three parts, $70 \%$ for training, $15 \%$ for validation and $15 \%$ for testing. This was chosen to give a reasonable compromise between training and stability and allowed comparison between the various choices of feature vector and data set described below.

In total, 35 probe points were assessed on this prostate, yielding 35 different target vectors of two elements or four elements (as described above). With this number, it was not effective to use a 4target output vector as the performance in validation and test could vacillate depending upon whether or not some of the classifications were actually represented in the validation or test set. Even with the 2-element target, the performance of the network over all categories was found to be a more reliable indicator of the presence (or absence) of a pattern than relying on the test performance alone.

Figure 1 shows the ANN Confusion Matrix for the base case, where the six-element feature vectors consisting of dynamic modulus, static modulus and phase angle at each of the frequencies were considered as independent measurements for each of the depths, i.e. $3 \times 35$ (105) input vectors. Looking first at the "All" confusion matrix, it can be seen that, over training, validation and test 40 of the 59 PCa targets were correctly classified (i.e. $68 \%$ sensitivity) and 29 of the 46 benign targets were correctly classified (i.e. $63 \%$ specificity). In the following sensitivity analysis, the overall ANN performance (square at bottom right of each $3 \times 3$ array) is used for comparison, the percentage correct for all runs and for the test set being recorded in Table 3. Comparing Figure 14 with Table 3 highlights the difficulty with the relatively small number of data sets, where the performance of the validation set and the test set are rather different, the test set indicating that the success rate is about the same as guessing and the validation set somewhat better than the overall.

It might be noted that Figure 13 only shows 28 of the 35 measurement points on this particular patient. This is because one histological slice was a little fragmented and spread over a number of slides, making it difficult to present in such an intuitive way as the four other sections (although the histology could be measured fairly reliably). If the base case is re-run on the 28 measurement points (i.e. $3 \times 28=84$ input vectors), the overall performance ( $74 \%$ sensitivity and $73 \%$ specificity) and the test performance are both somewhat better. Looking at Figure 13, the good performance on the 28 points is remarkable, given the evident heterogeneity in depth and coverage of the test column by the cancer-affected areas, not to mention the variation in column height and support conditions.

Returning to the base case (35 points), the remaining rows of Table 3 show the effect of selecting which mechanical indicators go into the feature vector. Considering both the "All" and "Test" sets, it seems that performance is generally made worse (or, at least, not any better) by the selection of particular elements of the 6-element vector. The exception to this is the static modulus whose presence in the feature vector seems to reduce sensitivity and specificity.

Although these results are encouraging, several other factors have not been taken into consideration, which, if they had, would almost certainly improve sensitivity and specificity. First of all, there is a pronounced edge effect (most evident at points 7, 8, 21 and 22 in Figure 14) where the modulus is low, most likely due to the probe engaging on a downward-sloping surface but also due to the reduced thickness of the tissue and poorer support on the anterior surface. Also, because the probed volume extends beyond the radius of the membrane, results in one column are likely to be 
affected by the adjacent columns, so that a cancer-free column adjacent to a column containing cancer may well give a different mechanical result to a cancer-free column with adjacent cancer-free columns. Finally, no shading has been applied for the clinical significance of the cancer such that points 6 and 23, say, would both be classified as "cancer".

\subsection{Between-patient variation (patient specificity)}

Across the cohort, some prostates only contained two types of tissue classification while others contained all four. Some prostates contained small multi-focal tumours while others contained a single large tumour. Thus, it might be expected that applying similar pattern-recognition techniques as applied to Patient 21 across the whole cohort would allow an assessment of the extent to which the mechanical features were indicative of fundamental differences in tissue structure associated with malignancy or other disease conditions. Figure 15 shows the confusion matrix corresponding to Figure 14 (cancer vs. benign using the six-element feature vector), this time for all 359 points listed in Table 1, measured at each of the three depths. For the "All" confusion matrix, the sensitivity is $60 \%$ and the specificity 54\%, both being rather worse than for the Patient 21 data (see lines 1 and 2, Table 4).

Because of the larger number of samples, it is possible to concatenate the feature vector to contain the measurements at all three depths, which is more realistic for an actual in vivo intervention. Figure 16 shows the relevant confusion matrices trained onto the two targets (cancer and benign) and the four targets listed in Table 1. For the "All" confusion matrix (Row 3, Table 4), the sensitivity and specificity are a bit closer to that for the Patient 21 data. As for Patient 21, removing the static modulus improves diagnostic performance significantly (Row 4, Table 4) although not to as high a level as when considering the nearest equivalent for Patient 21 only (Row 5, Table 4). For the four targets, it is possible to assess sensitivity to any disease (including BPH) and sensitivity to the presence of cancer separately and, as can be seen in Table 4. Here, both sensitivities and, indeed the specificity, are a relatively poor $52 \%$, although the numbers of samples are rather small, even in the "all" matrix. If, on the other hand, all points with a BPH or "Mixed" classification are removed, the sensitivity again improves although the specificity is not quite as good.

\section{Discussion}

\subsection{DIP device performance}

The DIP device described here was able to measure the complex modulus of excised whole prostates in an efficient way. The device was deployed at around 35 positions on each prostate gland giving complete coverage of the posterior surface (that accessible trans-rectally) at a spatial resolution limited only by the membrane diameter of $6 \mathrm{~mm}$. The soft actuator made minimal marking on the prostate gland, leaving specimens that could still be successfully used for histological analysis. The speed of the measurement protocol also meant that prostates could be completely assessed within an hour to reduce drying out of the tissue, thus minimising potential changes in the mechanical behaviour due to fluid loss over time. The speed of measurement per point and the relative softness 
of the probe means that the device configuration is suitable for trans-rectal deployment to measure the stiffness of the prostate gland in vivo.

From the calibration studies and from the ANN analysis, it is clear that the quasi-static modulus was the least discriminating of the three mechanical features and its exclusion from the feature vector either improved sensitivity and specificity or, at least, made no difference. It is thought that this is due to medium time (over a few tens of seconds) "fade" in the actuator associated with small leaks, and that a few changes to the design and data processing would help to improve the quality of this measurement while still having the probe deployable in vivo. The two frequencies chosen $(1 \mathrm{~Hz}$ and $5 \mathrm{~Hz}$ ) appeared to give complementary information in the feature vector and, although the device is capable of delivering higher frequencies, these were not used in the current study to maintain the calibration. There is a potential ambiguity in phase angle as the deployment of the device did not make it convenient to establish a time zero. Nevertheless, the phase features contain useful diagnostic information, although the absolute value of the phase is not known. A wider range of frequencies that allow a pattern of phase vs frequency to be established will add to the diagnostic power of the device.

\subsection{Stiffness measurements compared to other published values}

The advantage of the current probe is that it returns values that can be traced to measurement standards and so allows the use of data from other investigators to be used, provided that the measurement conditions are clearly known. The use of relatively low amplitude dynamic probing allows information on time constants to be obtained efficiently and the option of a variety of probed depths allows potential non-linearity in the stress-strain response to be assessed as well as allowing the probed volume to be varied. A final, and immensely powerful, advantage of making calibrated measurements in vivo is that, in conjunction with detailed mechanical modelling and/or simulation, it allows the development of structure-property relationships whose use can enhance iDRE and can, furthermore, lead to other applications, for example in surgery and in different types of soft tissue $(37,38)$.

The literature on prostate stiffness measurement reports a variety of methods and a variety of different units, some of them device-specific. More importantly, if they are even acknowledged, the effects of specimen and probe size, non-linearity of stress-strain response and temporal (or viscoelastic) behaviour are rarely examined systematically. Table 5 summarises the reported values of elastic or viscoelastic properties of prostate tissue, focussing on low frequency or low strain rate palpation measurements as opposed to those which involve ultrasonic or high frequency wave propagation (of which only one example, 39, is given). The variation in absolute values of modulus (from around $10 \mathrm{kPa}$ to a few hundred $\mathrm{kPa}$ ) is perhaps unsurprising, given the range in specimen size, strain rate and strain level used. One common conclusion amongst investigators, however, is that, within the method they have used, tissue affected by cancer is stiffer than "normal" tissue, although there is considerable disagreement about the magnitude and significance of the difference in the face of other variations in their respective datasets.

The investigators working with pieces of excised tissue (40) and $(25,26,27$ and 41 , all of whom used essentially the same test protocol) tend to report rather higher values of modulus, which could be explained by the expression of water from the samples leading to a more compacted material. In particular, Krouskop et al (40) reported a very large increase in elastic modulus in PCa specimens 
when tested with $4 \%$ pre-strain as opposed to $2 \%$ pre-strain. In common with $(25,26,27$ and 41$)$ and in contrast with (40), Zhang et al (42) observed viscoelastic (or, at least time-dependent) behaviour in their study on 17 prostate cores from the anterior regions of the prostates from 8 patients. Although the Kelvin-Voigt viscoelastic model they used is unsuitable for describing the stress-strain behaviour of materials, it is nevertheless helpful in describing the frequency (or strain rate) behaviour of the measurements. The values of dynamic modulus cited in Table 4 are at $150 \mathrm{~Hz}$, specifically used because of the authors' interest in applying the results to crawling wave elastography. Using the values they published for the K-V parameters, it is possible to calculate the mean values of dynamic modulus to be $3.61 \mathrm{kPa}$ for normal and $8.65 \mathrm{kPa}$ for $\mathrm{PCa}$ at $1 \mathrm{~Hz}$ and $5.10 \mathrm{kPa}$ for normal and $12.41 \mathrm{kPa}$ for $\mathrm{PCa}$ at $5 \mathrm{~Hz}$, indicating that the effect of frequency over this range is almost as much as the effect of tissue composition. The K-V model implies that there will be no change in phase difference with frequency. It should be emphasised here that the foregoing is based on extrapolation of a model, rather than direct observation. Furthermore, Zhang et al fitted the K-V model to relaxation curves over several hundred seconds, and it is well-known (e.g. Palacio-Torralba et al, 47) that it is very difficult to fit a single time constant (as demanded by the K-V model) to relaxation curves, the tendency being to obtain a principal time constant approximately equal to the length of observation. The results of the very detailed measurements of Muruyama et al (43) make plain the need for a multi-scale approach in understanding the structure-property relationship in such a heterogeneous and complex structure as the prostate gland.

The advantage of working with prostate pieces is that the local tissue condition can be assessed carefully, but, as discussed above, this can give problems in obtaining a realistic (from the point of view of clinical application) measure of mechanical properties. Of the three systematic studies on whole prostates (including the current one) only one (45) reports unambiguously a statistically significant difference between the moduli (however measured) associated with normal and cancerous tissue, the remaining two suggesting the specificity (i.e. the variability within "normal" tissue) to be a greater issue than sensitivity, a general finding echoed in all studies. All three of the whole prostate studies used a similar maximum strain, although only the current study uses an oscillating probe with a relatively small range of strain (for the dynamic modulus). Ahn and Kim (45) used a strain rate that is similar to the current study for the quasi-static modulus, which corresponds to holding of the mean indentation over several oscillations (typically a few seconds), whereas the oscillatory strain rates (approximately amplitude divided by one quarter of a period) are up to two orders of magnitude higher. The strain rates used by Carson et al (44) are around an order of magnitude lower than those used by Ahn and Kim, making them the slowest of the three. Two of the three studies (present one and 46) on whole prostates have used the Hertzian contact model to determine modulus from the force and indentation depth, which requires an assumption of a value for Poisson's ratio, although, in later work, Kim et al (46) have refined their analysis using an FE model, leading to a slightly reduced value for normal tissue and a more substantial increase for PCa. At face value, then, the current study (quasi-static modulus) is in agreement with the measurement of Ahn and Kim for normal tissue, although in stark disagreement with their value for PCa. The measurements of Carson et al yielded a substantially higher elastic modulus, although there is no direct comparator in the other two studies due to the much lower strain rate used. Similarly, the dynamic modulus and PD from the current study have no direct comparator in other whole prostate studies. 
The key question in whole prostate studies is, however, how best to distinguish between healthy and diseased prostate during an examination, whether using sonoelastography or purely mechanical palpation, or a combination of both. Ahn and Kim measured 21 points on the posterior surfaces of 35 prostates using a smaller probe than the one used in the current work, but also with a relatively small depth of indentation. Instead of carrying out a point-by-point statistical analysis, they mapped the pathology of each prostate, dividing it into those regions classified as cancerous and normal and then compared measured and estimated properties from the map (although this process is not entirely clear). Carson et al, (44) assessed a total of 32 prostates, 26 of which were from radical prostatectomies. They measured stiffness with a $12 \mathrm{~mm}$ diameter steel ball-end probe, recording the force as the probe was advanced into the surface by $30 \%$ of its thickness (typically $9 \mathrm{~mm}$ ) and retracted again over a period of 6-10min, using the rate of change of force with position immediately on unloading (so-called Oliver-Pharr stiffness) to determine the elastic modulus which they simply calculated from the force divided by hemispherical surface area. They probed five points on each prostate and carried out some additional measurements on slices $6-10 \mathrm{~mm}$ thick for a closer correlation between histology and measurement. For the whole prostates, they reported a median Young's modulus of $43.2 \mathrm{kPa}$ with a SD of 59.8. The corresponding values for prostates with palpable abnormalities was $46.5 \pm 22.2$ and $31 \pm 63.1$ from which they were able to conclude only that prostates with cancer were stiffer. Although they do not specifically measure an elastic constant, the preliminary study on a whole excised prostate gland carried out by Astrand et al [48] needs also to be mentioned here. Using the resonance sensor referred to earlier (22), they have reported a statistically significant difference in dynamic stiffness between areas considered to contain cancer and other areas of the prostate.

\section{3 Implications of findings for in vivo deployment}

The probe, as described here, is immediately deployable in vivo by mounting it on a surgeon's index finger under a glove for trans-rectal insertion, essentially delivering it as in conventional DRE. A typical DRE on a non-anaesthetised patient will last for the order of a few minutes, so it is important to reduce the number of measurements and the number of points to the minimum necessary to establish the condition. On anaesthetised patients, this is less of a problem, although interventions should still be kept as short as possible.

Since the probe does not currently have a location device and its manoeuvrability in situ is limited, the attitude of the probe and the exact position are only known with respect to anatomical references such as the bladder neck and the anal sphincter which the practitioner can sense directly. Taking a small number of points (6-8) against the references of top, bottom, left and right ensures at least that there is coverage of the palpable region accessible thought the rectum.

Finally, the applied force and the constraint are, to an extent, patient- and operator-specific so these could also affect the measurements and hence the capacity of the probe to distinguish tissue condition. Modelling work based on patient MRI scans by Palacio-Torralba et al [30], has suggested that the local anatomy of the patient as well as the intrabladder pressure can have a significant effect on the apparent stiffness. The effects of the overlying glove and the rectal wall, along with the operator's subjective assessment of light, medium and heavy contact pressure will also serve to blur the measurements somewhat. On the positive side, however, it is well-known that, despite patientspecific variations, prostate cancer is manually palpable using conventional DRE with reasonable inter-operator agreement, so the prospect of a meaningful measurement is good. 


\section{Conclusions}

The advantage of the current probe is that it returns values that can be traced to measurement standards and so allows the use of data from other investigators in its detailed design and development of measurement protocols, provided that the measurement conditions are clearly known. The use of relatively low amplitude dynamic probing allows information on time constants to be obtained efficiently and the option of a variety of probed depths allows potential non-linearity in the stress-strain response to be assessed as well as allowing the probed volume to be varied. A final, and immensely powerful, advantage of making calibrated measurements in vivo is that, in conjunction with detailed mechanical modelling and/or simulation, it allows the development of structure-property relationships whose used can enhance iDRE and can, furthermore, lead to wider applications, for example in surgery and in different types of soft tissue

This work reports the first measurements of the dynamic mechanical properties of whole excised prostates. The dynamic modulus is around $20 \mathrm{kPa}$ at $1 \mathrm{~Hz}$ and around $14 \mathrm{kPa}$ at $5 \mathrm{~Hz}$. The method also allows a measurement of the quasi-static modulus from the mean stress, effectively applied over the few seconds' duration of a single point measurement, and values of around 14kPa were measured. Although not directly comparable in terms of allowed relaxation times, the values determined are in broad accord with the findings of the two other reported systematic studies of whole excised prostates.

Whilst there was no single mechanical measure which yielded a generalised statistically significant difference between diseased and normal tissue, combinations of the mechanical measures were found to give sensitivity and specificity of up to $78 \%$ and $75 \%$, respectively, applied to a single patient and $73 \%$ and $62 \%$ when applied to all 11 patients. This performance could have been improved by taking into account such factors such as edge effects, overlap and clinical significance of the cancer.

In its current state of development, the device is deployable in vivo and was designed as such. This necessitated a number of compromises in the degree of control of load and displacement, which ultimately means that each embodiment has its own dynamic properties. A few modifications will suffice to improve the sensitivity of the device. Changes in the measurement protocol would also allow a wider range of time constants to be assessed and improve the precision of the assessment of the quasi-static modulus. 
Future areas of research include the deployment of the probe in vivo, the use of a wider panel of diagnostic indicators, miniaturisation and modelling of the tissue histological structure to allow a more robust structure-property relationship to be devised.

\section{Acknowledgements}

The authors acknowledge the support of the Engineering and Physical Sciences Research Council under grant nos. (EP/I019472/1, EP/I020101/1 and EP/K036939/1).

\section{References}

1. Jemal A, Bray F, Center MM, Ferlay J, Ward E, Forman D. Global cancer statistics. CA Cancer J Clin. 2011 Mar 1;61(2):69-90.

2. Gambert SR. Screening for prostate cancer. Int Urol Nephrol. 2001 Jun 1;33(2):249-57.

3. Goddi A, Sacchi A, Magistretti G, Almolla J. Transrectal real-time elastography of the prostate: Normal patterns. J Ultrasound. 2011 Diciembre;14(4):220-32.

4. Pallwein L, Mitterberger M, Struve P, Pinggera G, Horninger W, Bartsch G, et al. Real-time elastography for detecting prostate cancer: preliminary experience. BJU Int. 2007 Jul;100(1):42-6.

5. Kundra V. Prostate Cancer Imaging. Semin Roentgenol. 2006 Abril;41(2):139-49.

6. Auvinen A, Moss SM, Tammela TL, Taari K, Roobol MJ, Schröder FH, et al. Absolute Effect of Prostate Cancer Screening: Balance of Benefits and Harms by Center within the European Randomized Study of Prostate Cancer Screening. Clin Cancer Res Off J Am Assoc Cancer Res. 2016 Jan 1;22(1):243-9.

7. Gleason DF. Histologic grading of prostate cancer: A perspective. Hum Pathol. 1992 Mar;23(3):273-9.

8. Epstein JI. An Update of the Gleason Grading System. J Urol. 2010 Feb;183(2):433-40.

9. Garra BS. Imaging and Estimation of Tissue Elasticity by Ultrasound. Ultrasound Q Dec 2007. 2007;23(4):255-68.

10. Ophir J, Céspedes I, Ponnekanti H, Yazdi Y, Li X. Elastography: A quantitative method for imaging the elasticity of biological tissues. Ultrason Imaging. 1991 Apr;13(2):111-34.

11. Hoskins PR. Principles of ultrasound elastography. Ultrasound. 2012 Jan 2;20(1):8-15.

12. Pallwein L, Mitterberger M, Pinggera G, Aigner F, Pedross F, Gradl J, et al. Sonoelastography of the prostate: Comparison with systematic biopsy findings in 492 patients. Eur J Radiol. 2008 Feb;65(2):304-10.

13. V. Litwiller D, K. Mariappan Y, L. Ehman R. Magnetic Resonance Elastography. Curr Med Imaging Rev. 2012 Feb 1;8(1):46-55.

14. Arani A, Plewes D, Chopra R. Transurethral prostate magnetic resonance elastography: Prospective imaging requirements. Magn Reson Med. 2011 Feb;65(2):340-9. 
15. Chopra R, Arani A, Huang Y, Musquera M, Wachsmuth J, Bronskill M, et al. In vivo MR elastography of the prostate gland using a transurethral actuator. Magn Reson Med. $2009 \mathrm{Jul}$ 1;62(3):665-71.

16. Arani A, Plewes D, Krieger A, Chopra R. The feasibility of endorectal MR elastography for prostate cancer localization. Magn Reson Med. 2011 Dec;66(6):1649-57.

17. Li S, Chen M, Wang W, Zhao W, Wang J, Zhao X, et al. A Feasibility Study of MR Elastography in the Diagnosis of Prostate Cancer at 3.0T. Acta Radiol. 2011 Jan 4;52(3):354-8.

18. Sahebjavaher RS, Nir G, Gagnon LO, Ischia J, Jones EC, Chang SD, et al. MR elastography and diffusion-weighted imaging of ex vivo prostate cancer: quantitative comparison to histopathology. NMR Biomed. 2015 Enero;28(1):89-100.

19. Good D W et al., Elasticity as a biomarker for prostate cancer: a systematic review. $\mathrm{Br} \mathrm{J}$ Urol International, 2014, 113, pp. 523-534.

20. Panteliou SD, Tzortzis V, Anagnostopoulos GT, Sunaric MM, Sarris J, Hatzimouratidis K, et al. Development of a New Optical Device and Its Feasibility in Prostate Cancer Detection. Urol Int. 2012;89(3):290-5.

21. Jalkanen V, Andersson BM, Bergh A, Ljungberg B, Lindahl OA. Resonance sensor measurements of stiffness variations in prostate tissue in vitro-a weighted tissue proportion model. Physiol Meas. 2006 Nov 10;27(12):1373.

22. Jalkanen V, Andersson BM, Bergh A, Ljungberg B, Lindahl OA. Prostate tissue stiffness as measured with a resonance sensor system: a study on silicone and human prostate tissue in vitro. Med Biol Eng Comput. 2006 Jul;44(7):593-603.

23. Jalkanen V, Andersson BM, Bergh A, Ljungberg B, Lindahl OA. Explanatory models for a tactile resonance sensor system-elastic and density-related variations of prostate tissue in vitro. Physiol Meas. 2008 Jul 1;29(7):729-45.

24. Jalkanen V, Andersson BM, Bergh A, Ljungberg B, Lindahl OA. Indentation loading response of a resonance sensor-discriminating prostate cancer and normal tissue. J Med Eng Technol. 2013 Oct;37(7):416-23.

25. Yang THJ, Leung SKW, Phipps S, Reuben RL, McNeill SA, Habib FK, et al. In-vitro dynamic microprobing and the mechanical properties of human prostate tissues. Technol Health Care Off J Eur Soc Eng Med. 2006;14(4-5):281-96.

26. Phipps S, Yang THJ, Habib FK, Reuben RL, McNeill SA. Measurement of tissue mechanical characteristics to distinguish between benign and malignant prostatic disease. Urology. 2005 Aug;66(2):447-50.

27. Yang, $\mathrm{T}$ H J et al. Dynamic instrumented palpation (DIP) - a new method for soft tissue quality assessment: application to prostate disease diagnosis, submitted to Proceedings IMechE, Part H, Journal of Engineering in Medicine, 2016

28. Åstrand A P et al. Initial measurements on whole human prostate ex vivo with a tactile resonance sensor in order to detect prostate cancer, IFMBE Proceedings, 2015, 48, pp. 120-123. 
29. Kim Y, Ahn B, Na Y, Shin T, Rha K, Kim J. Digital rectal examination in a simulated environment using sweeping palpation and mechanical localization. Int J Precis Eng Manuf. 2014 Jan 9;15(1):169-75.

30. Palacio-Torralba J et al. Patient specific modelling of palpation-based prostate cancer diagnosis: effects of pelvic cavity anatomy and intrabladder pressure, Int. J. Numer. Methods in Biomed. Eng., 2016, 32(1), pp. 1-13

31. BS EN 60601-1:2006 +A11:2011 Medical electrical equipment - Part 1: General requirements for basic safety and essential performance [Internet]. The British Standards Institution; 2012. Available from: https://bsol.bsigroup.com/en/Bsol-Item-DetailPage/?pid=000000000030256124

32. Yang T H J et al., Dynamic instrumented palpation (DIP) - a new method for soft tissue quality assessment; application to engineered mechanical phantom materials. Biomedical Physics and Engineering Express, 2017, 3(2), 025103

33. MCNeill SA, Reuben RL. Apparatus for mapping biological tissue quality. US2006051734 (A1), 2006 .

33. Fung Y-C. Biomechanics: Mechanical Properties of Living Tissues. Springer; 1993. 590 p.

34. Scanlan, P., Hammer, S. J., Good, D., Shu, W., Reuben, R. L., Phipps, S., Stewart, G. A. \& McNeill, S. A. (2015) Development of a novel actuator for the dynamic palpation of soft tissue for use in the assessment of prostate tissue quality. Sensors and Actuators A (Physical), 232, pp 310-318

35. Scanlan P, Hammer SJ, Shu W, Reuben RL. A Scalable, Minimal Contact Device for the Characterization of Elastomer Membrane Deformation. Procedia Eng. 2014;87:508-11.

36. Weisenhorn AL, Khorsandi M, Kasas S, Gotzos V, Butt H-J. Deformation and height anomaly of soft surfaces studied with an AFM. Nanotechnology. 1993;4(2):106.

37. Posnansky 0 . On the influence of microscopic architecture elements to the global viscoelastic properties of soft biological tissue. Physica D. 2014, 289:1-11.

38. Palacio-Torralba, J et al. Histology-based homogenization analysis of soft tissue: application to prostate cancer. J. Roy. Soc. Interface 2017 14, 20170088; DOI: 10.1098/rsif.2017.0088.

39. Parker KJ, Huang SR, Lerner RM, Lee, F. J, Rubens D, Roach D. Elastic and ultrasonic properties of the prostate. In: Ultrasonics Symposium, 1993 Proceedings, IEEE 1993. 1993. p. 1035-8 vol.2.

40. Krouskop TA, Wheeler TM, Kallel F, Garra BS, Hall T. Elastic Moduli of Breast and Prostate Tissues under Compression. Ultrason Imaging. 1998 Oct 1;20(4):260-74.

41. Phipps $S$ et al., Measurement of the mechanical characteristics of benign prostatic tissue: a novel method for assessing benign prostatic disease, Urology, 2005, 65(3), pp. 1024-1028.

42. Zhang $\mathrm{M}$ et al. Quantitative characterization of viscoelastic properties of human prostate correlated with histology, Ultrasound in Med. and Biol., 2008, 34(7), pp. 1033-1042. 
43. Murayama Y, Omata S, Yajima T, Peng Q, Shishido K, Peehl DM, et al. High Resolution Regional Elasticity Mapping of the Human Prostate. In: Engineering in Medicine and Biology Society, 2007 EMBS 2007 29th Annual International Conference of the IEEE. 2007. p. 5802-5.

44. Carson WC, Gerling GJ, Krupski TL, Kowalik CG, Harper JC, Moskaluk CA. Material characterization of ex vivo prostate tissue via spherical indentation in the clinic. Med Eng Phys. 2011 April;33(3):302-9.

45. Ahn B and Kim J. Measurement and characterization of soft tissue behavior with surface deformation and force response under large deformations. Med Image Anal. 2010 April;14(2):138-48

46. Kim Y, Ahn B, Lee JW, Rha KH and Kim J. Local property characterisation of prostate glands using inhomogeneous modeling based on tumor volume and location analysis, Med Biol Eng Comput, 2013, 51, 197-205.

47. Palacio-Torralba, J., Hammer, S., Good, D.W., Alan McNeill, S., Stewart, G.D., Reuben, R.L., Chen, Y., 2015a. Quantitative diagnostics of soft tissue through viscoelastic characterization using timebased instrumented palpation. J. Mech. Behav. Biomed. Mater. 41, 149-160

48. Åstrand A P et al. Initial measurements on whole human prostate ex vivo with a tactile resonance sensor in order to detect prostate cancer, IFMBE Proceedings, 2015, 48, pp. 120-123 
Figure 1: The main components of the probe end of the prototype in vivo DIP device. The strain sensor and the force sensor on the rear of the device are visible through the transparent membrane and body materials. 

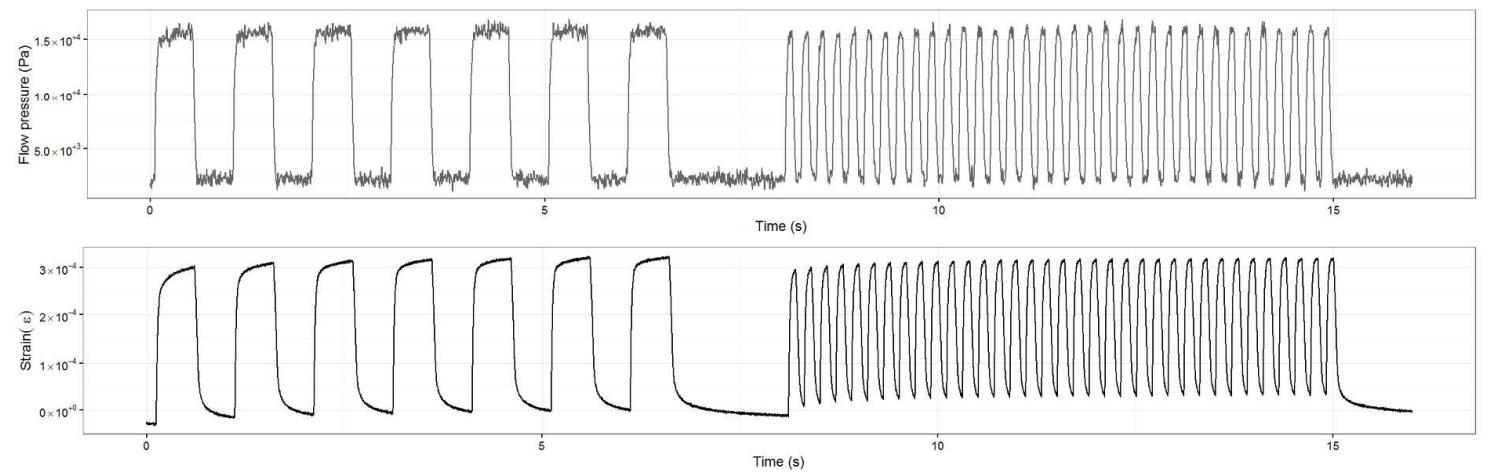

Figure 1: An actuation waveform (top) used to actuate the membrane on the DIP device. The strain waveform (bottom) shows the response of the membrane when applied to the prostate gland and actuated. The figure shows $1 \mathrm{~Hz}$ (left) and $5 \mathrm{~Hz}$ (right) portions of the actuation waveform. 

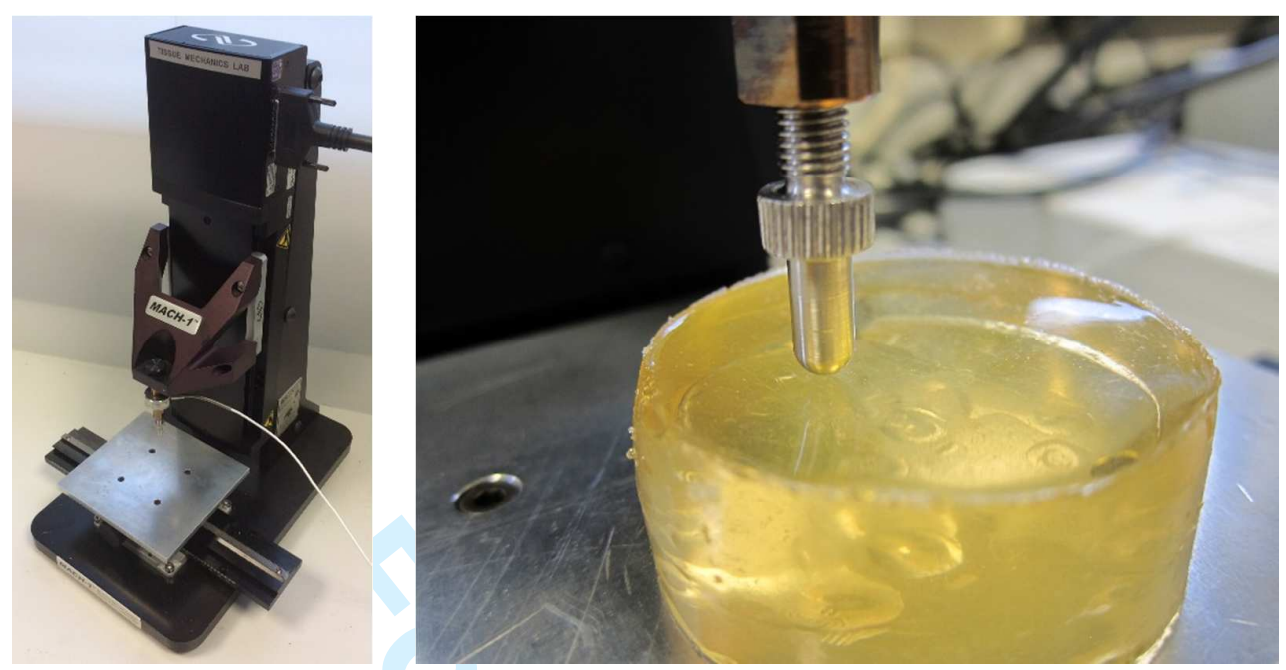

Figure 1: The Biomomentum Mach-1 indentation materials tester.Left - a view of the whole tester. Right-a closeup of the $6 \mathrm{~mm}$ diameter hemispherical indenter being applied to a $3 \mathrm{~g}$ gelatine sample. 


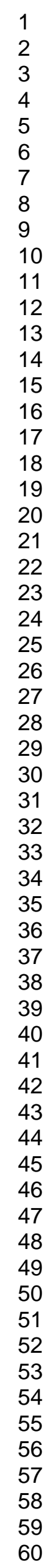

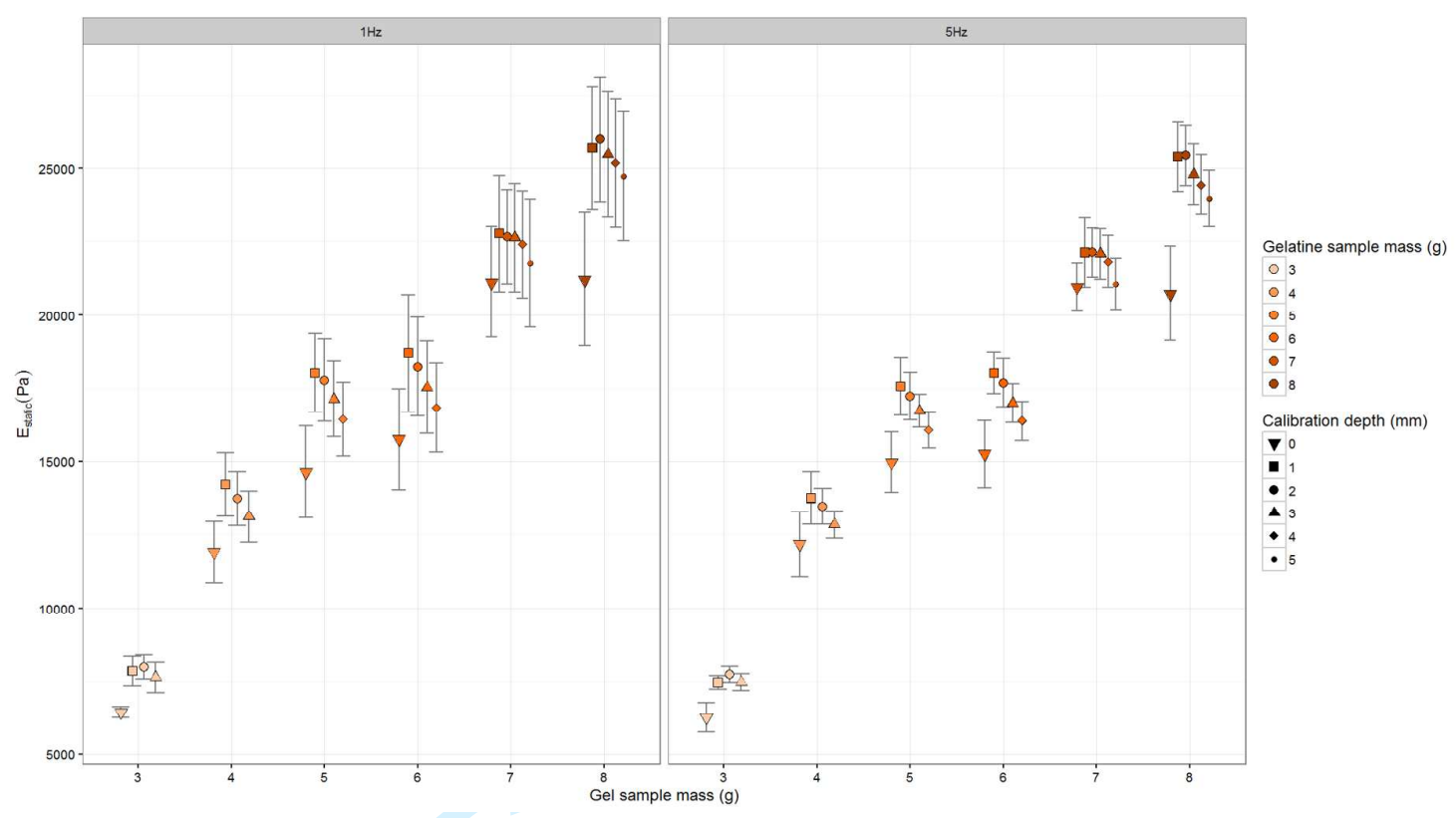

Figure 1: Static elastic moduli of gelatine samples used in calibration as measured by Mach-1 probe. 


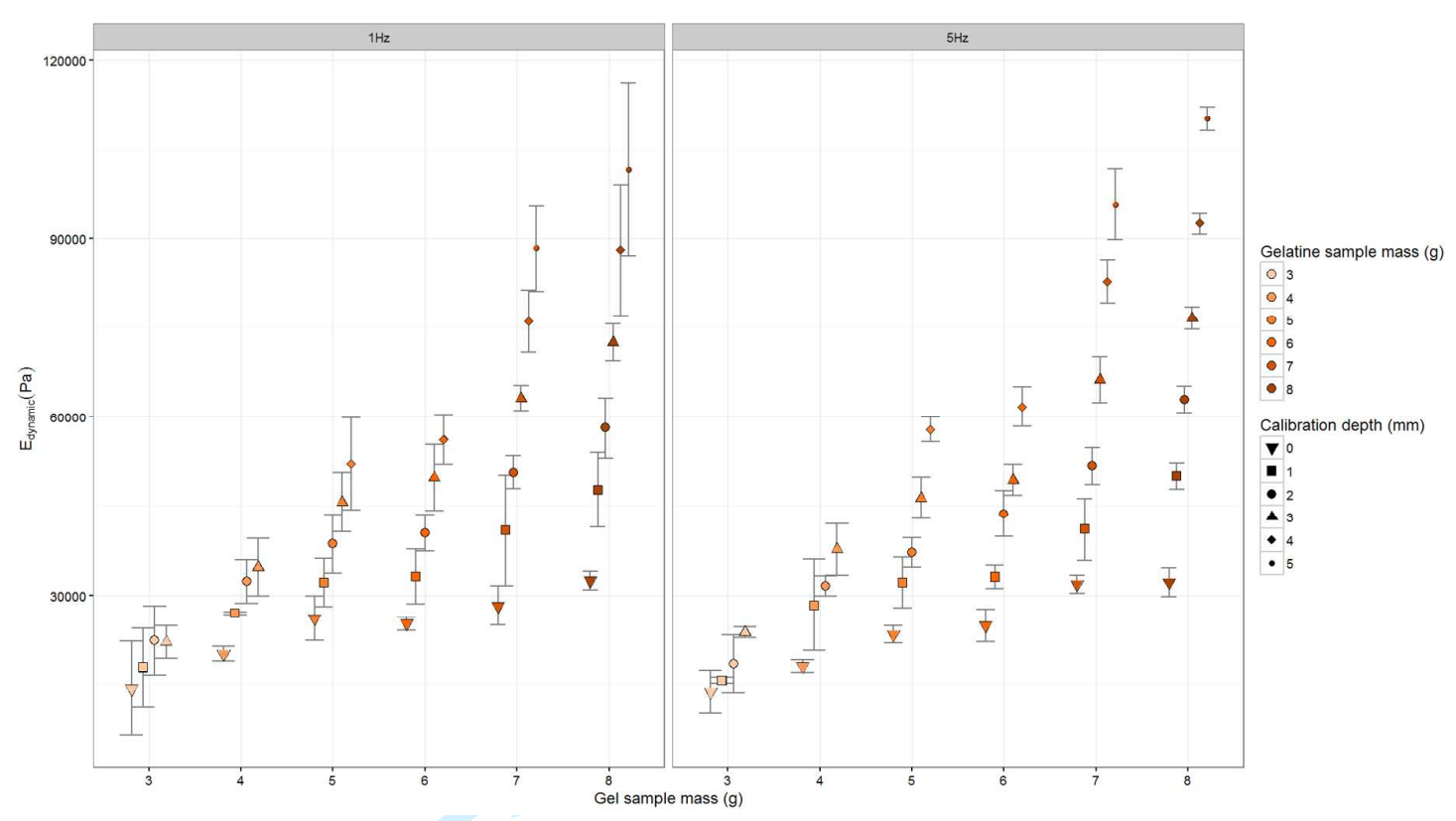

Figure 1: Dynamic elastic moduli of gelatine samples used in calibration as measured by Mach-1 probe. 


1
2
3
4
5
6
7
8
9
10
11
12
13
14
15
16
17
18
19
20
21
22
23
24
25
26
27
28
29
30
31
32
33
34
35
36
37
38
39
40
41
42
43
44
45
46
47
48
49
50
51
52
53
54
55
56
57
59
60

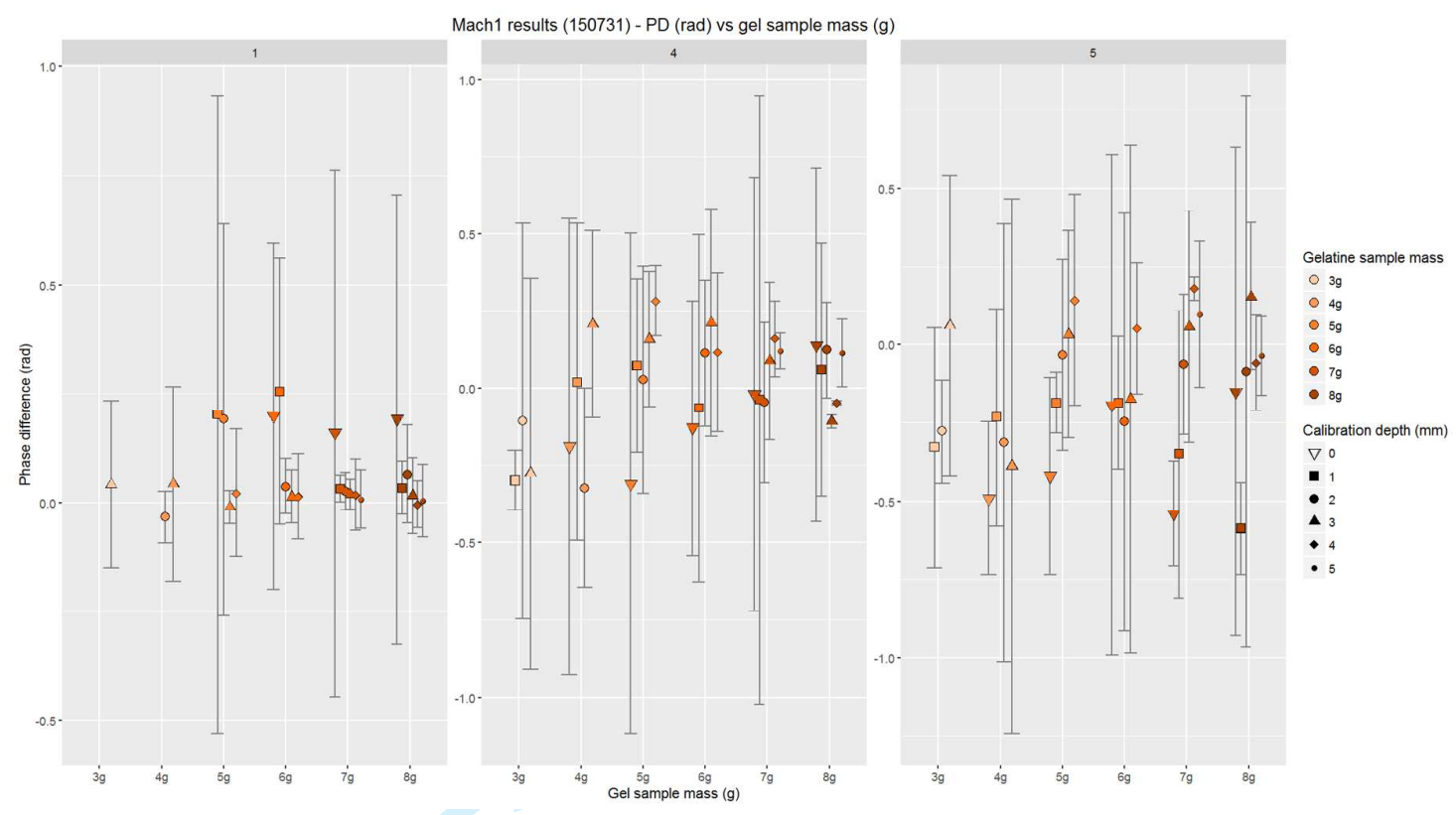

Figure 6: Phase difference of gelatine samples used in calibration as measured by Mach-1 probe at $1 \mathrm{~Hz}$ (left), $4 \mathrm{~Hz}$ (middle) and $5 \mathrm{~Hz}$ (right). 


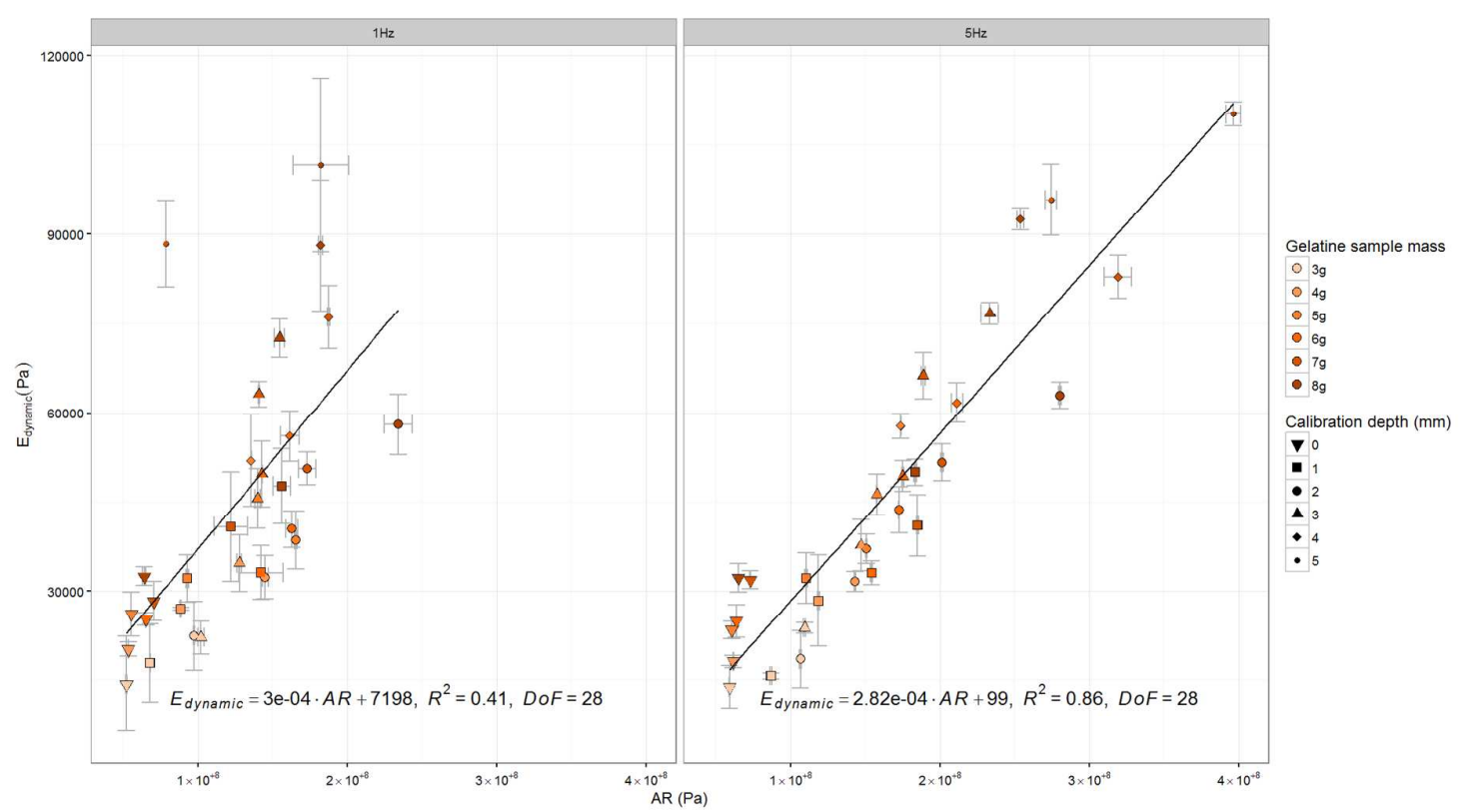

Figure 7: Calibration results for amplitude ratio measured by DIP device and dynamic modulus from the Mach-1. 


\section{Page 27 of 40}

Journal name

1

2

3

4

5

6

7

8

9

10

11

12

13

14

15

16

17

18

19

20

21

22

23

24

25

26

27

28

29

30

31

32

33

34

35

36

37

38

39

40

41

42

43

44

45

46

47

48

49

50

51

52

53

54

55

56

57

58

59

60

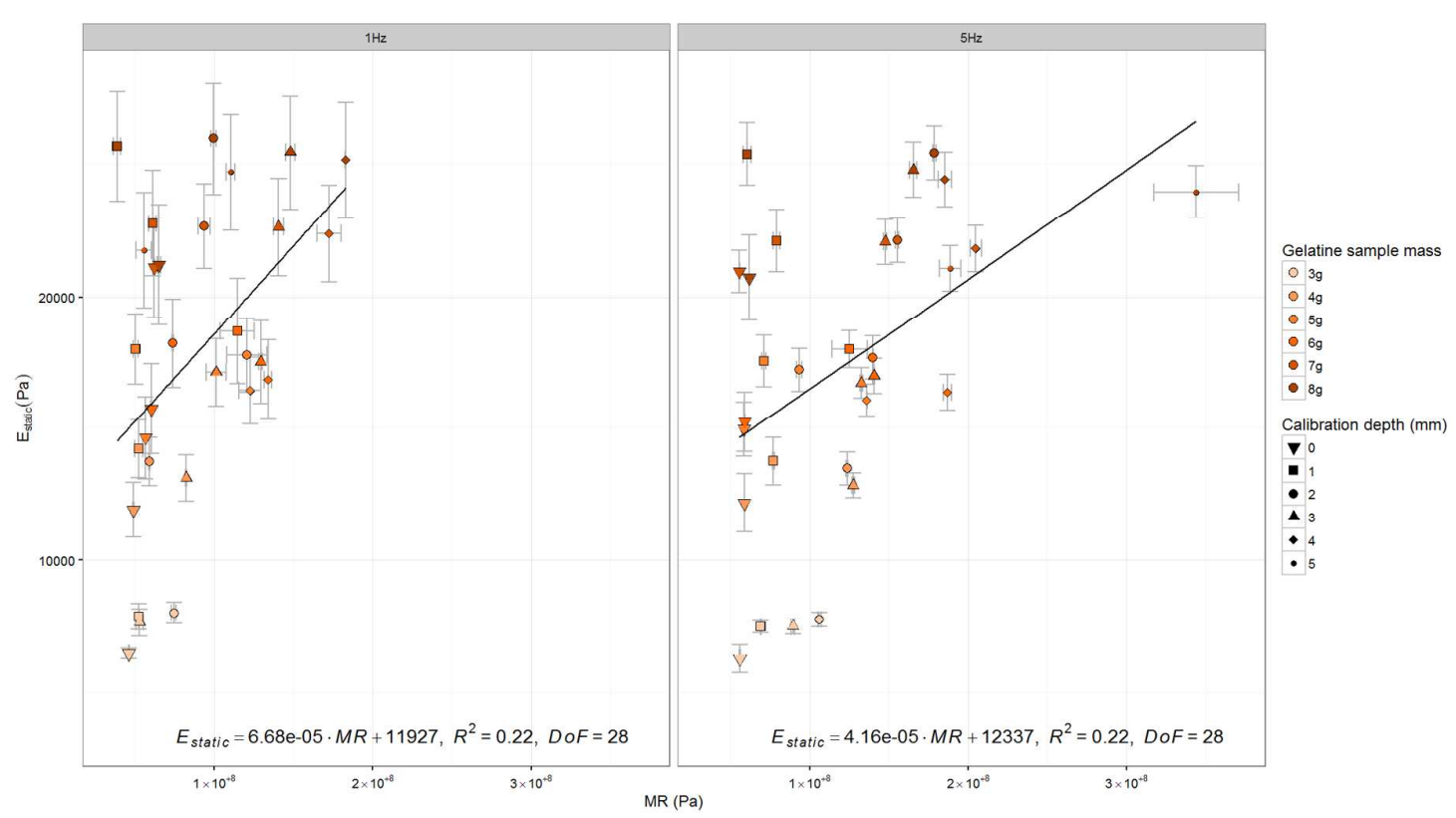

Figure 8: Calibration results for mean ratio measured by DIP device and quasi-static modulus from the Mach-1. 

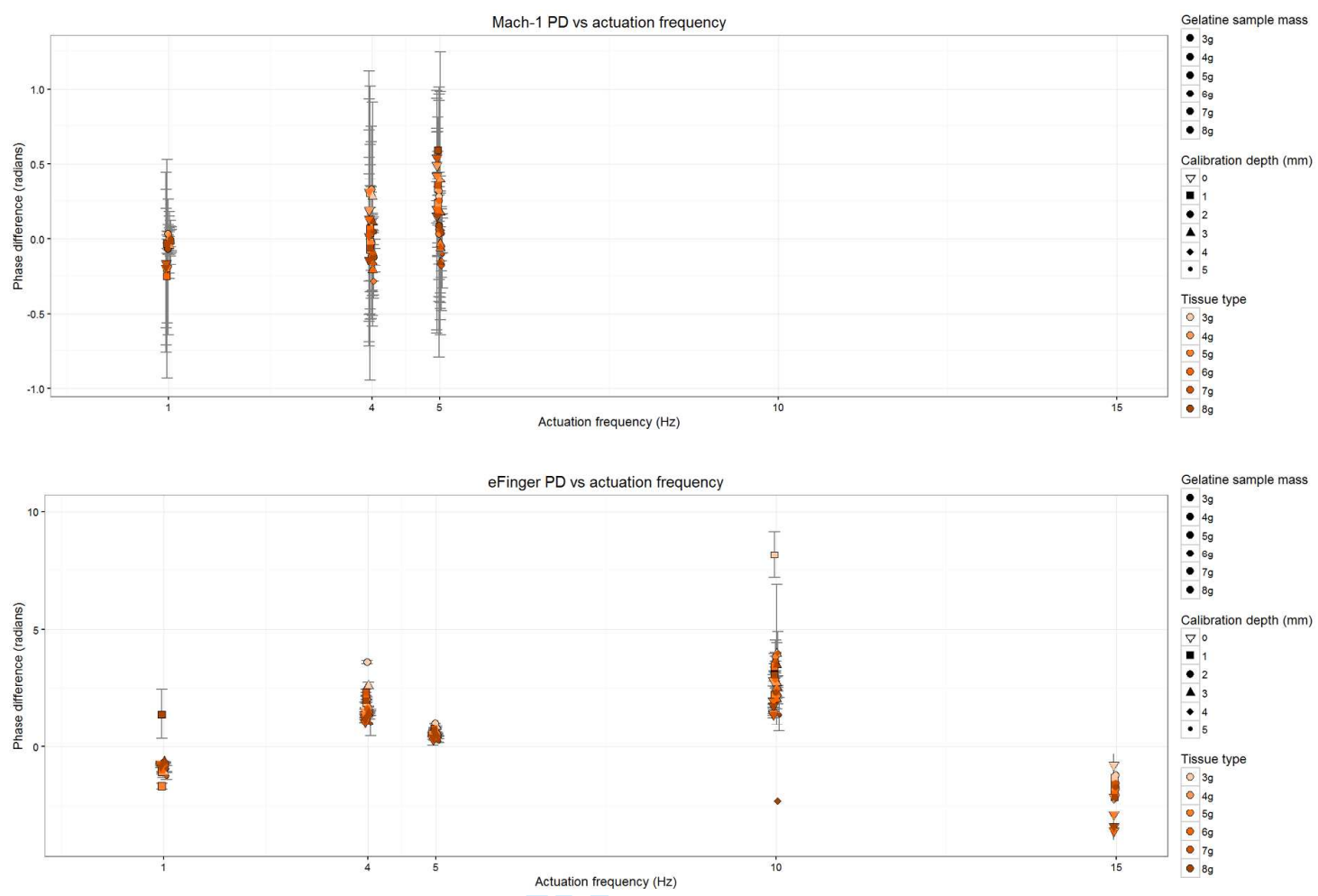

Figure 9: Calibration results for phase difference measured by DIP device (bottom) and from the Mach-1 (top). 


\section{Page 29 of 40}

2
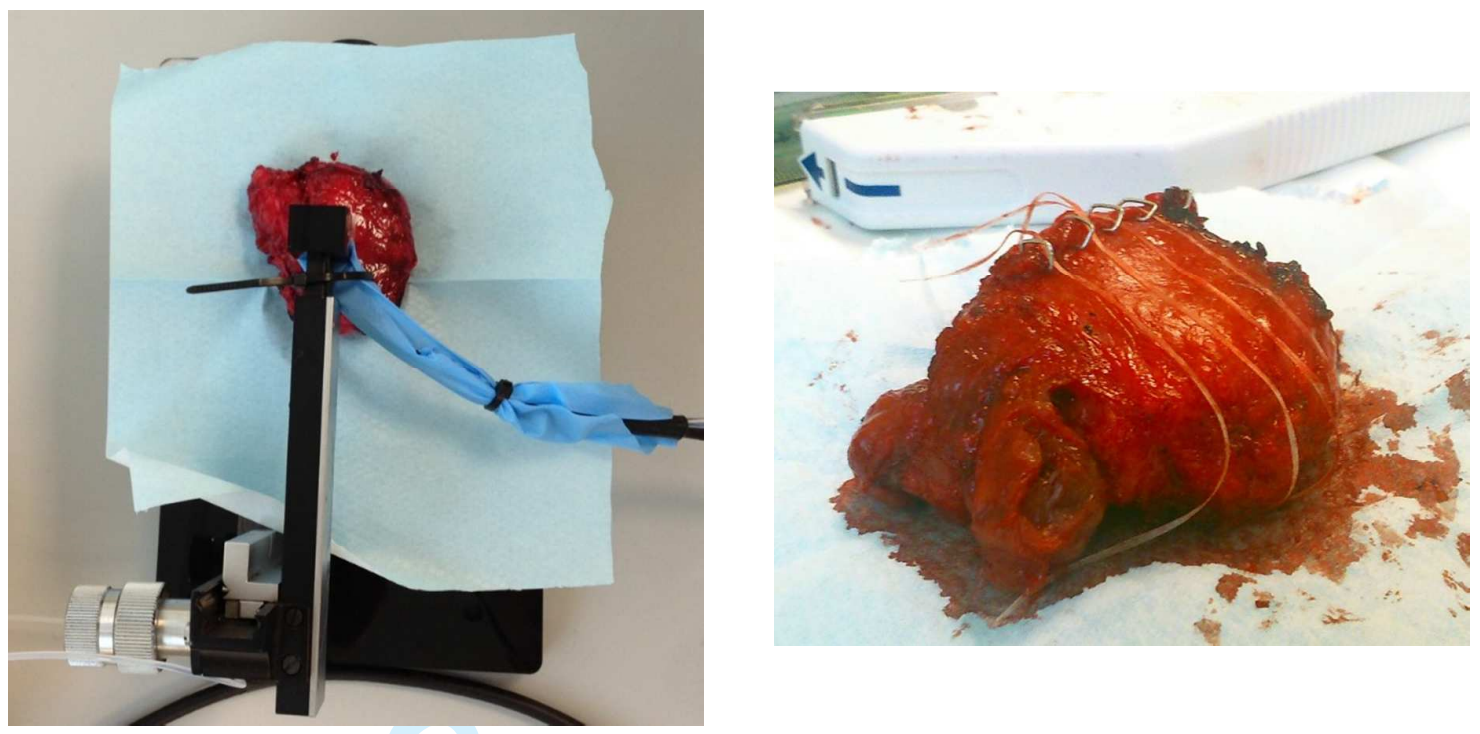

Figure 10: Locating the DIP device on the ex vivo prostate. The device was presented to the posterior surface of the prostate under a sheath using an XYZ table (left). The position of each row measured on the prostate was marked using thread (right) as a guide to the positioning of the DIP device. Surgical clips were inserted to mark the position of each row of measurements to allow a histological section to be prepared at the correct axial position. 
Figure 11: Typical probing sequence on posterior surface. Left, plan view showing points pitched at 6mm apart. Right, transverse histological section at A-A with areas of PCa outlined, showing typical column of assessment (point 11). Number of probe points depends on size of gland. 


\section{Page 31 of 40}

Journal name

1

2

3

4

5

6

7

8

9

10

11

12

13

14

15

16

17

18

19

20

21

22

23

24

25

26

27

28

29

30

31

32

33

34

35

36

37

38

39

40

41

42

43

44

45

46

47

48

49

50

51

52

53

54

55

56

57

58

59

60

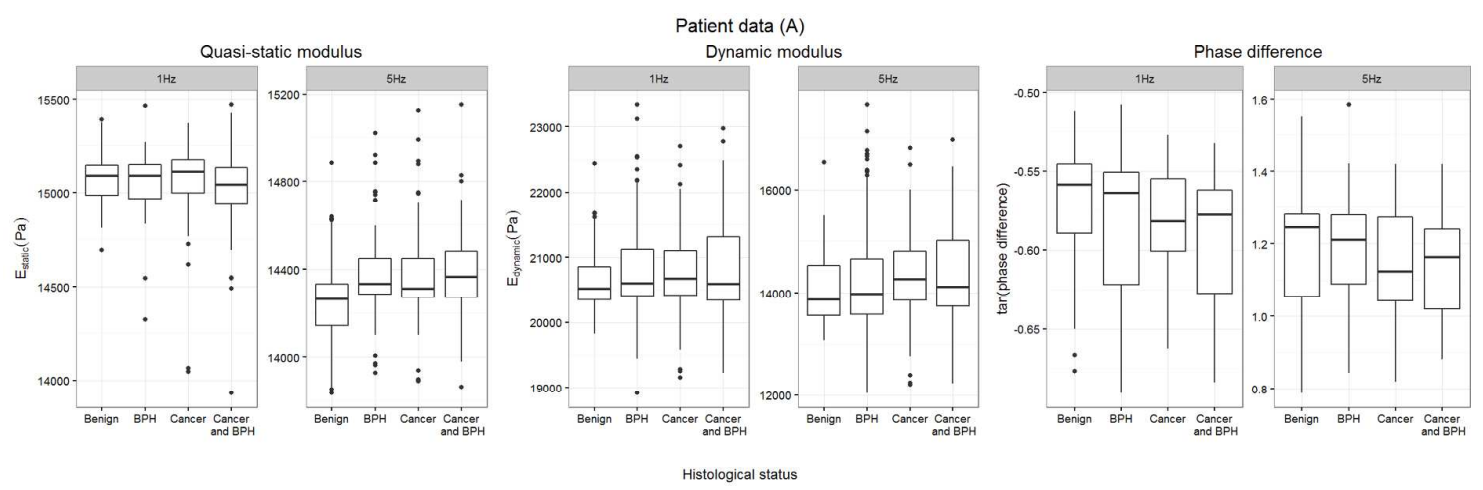

Figure 12: Boxplots showing quasi-static modulus, dynamic modulus and phase difference for 11 prostates assessed with a mean depth of $3 \mathrm{~mm}$. 

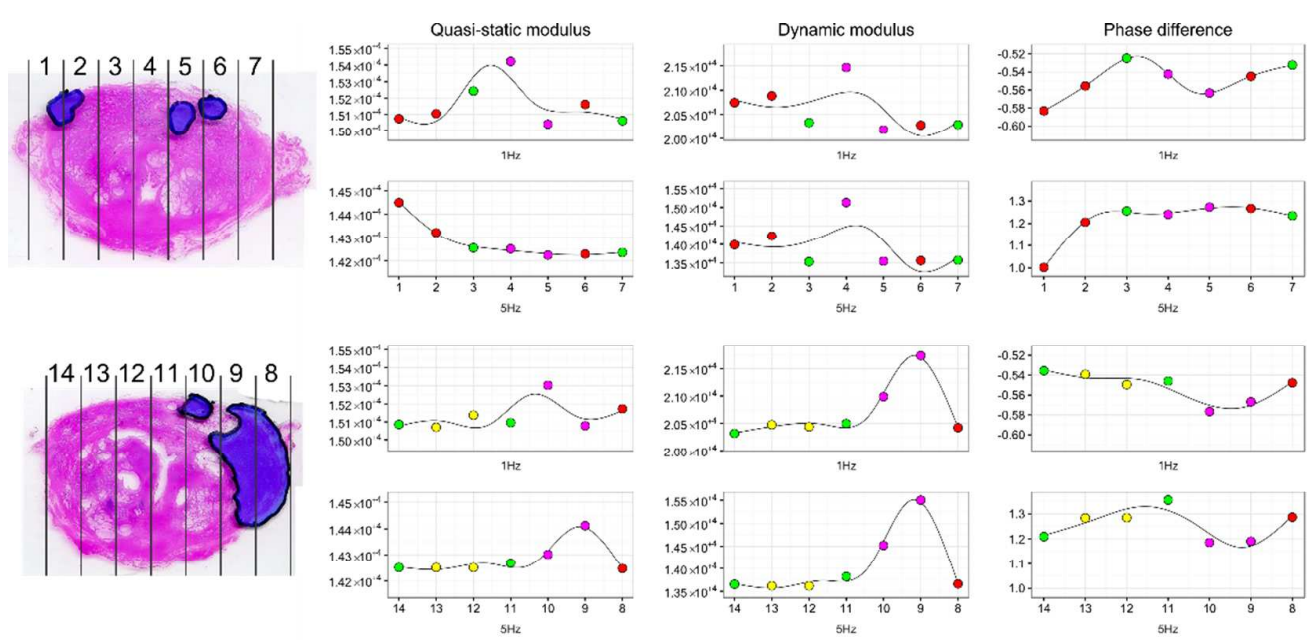

Figure 13: Histological sections and point probe measurements (Patient 21) 

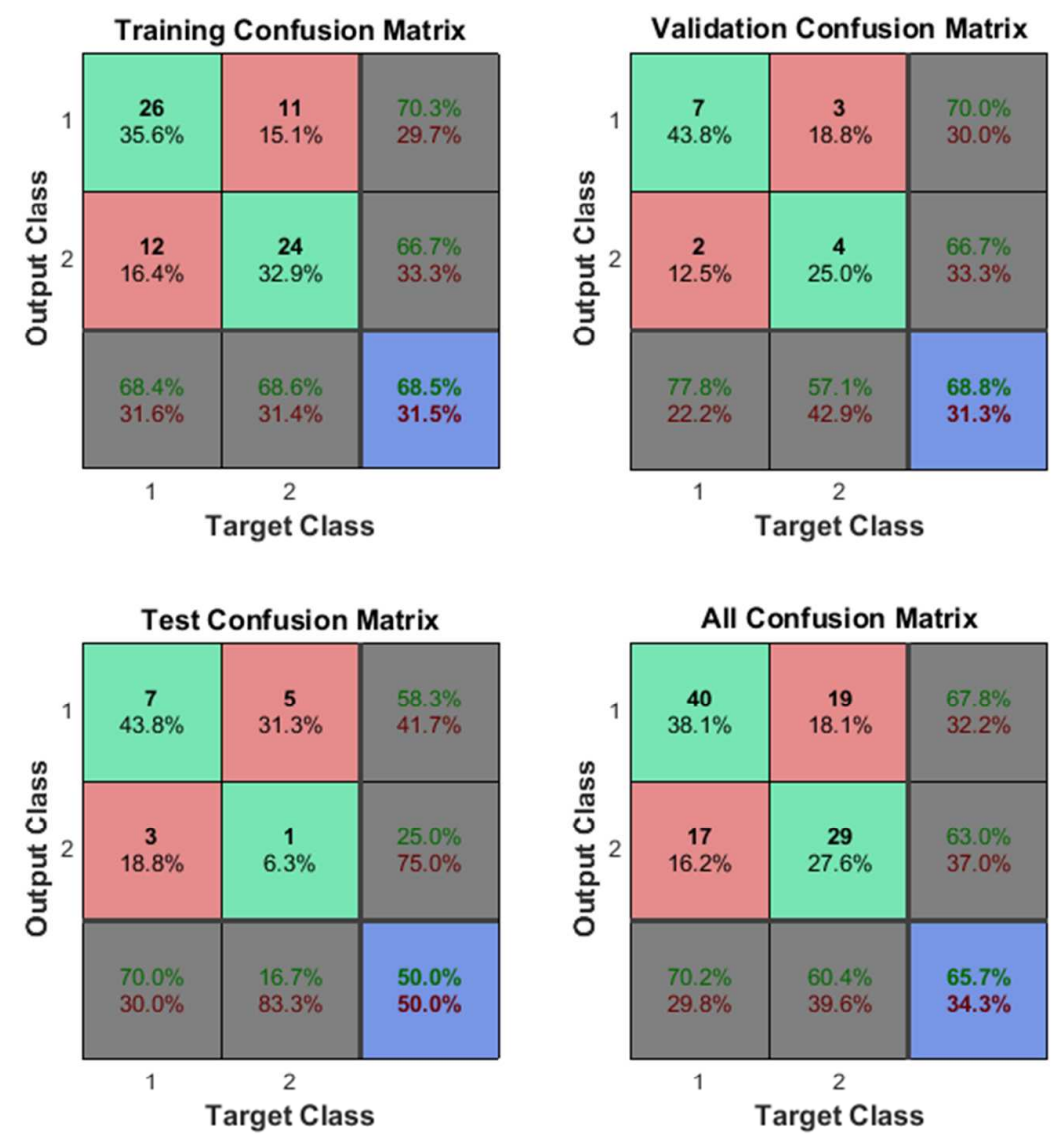

Figure 14: Confusion matrix for P21 using six-element features and all depths. Target Class 1 is PCa and Target Class 2 is benign. 

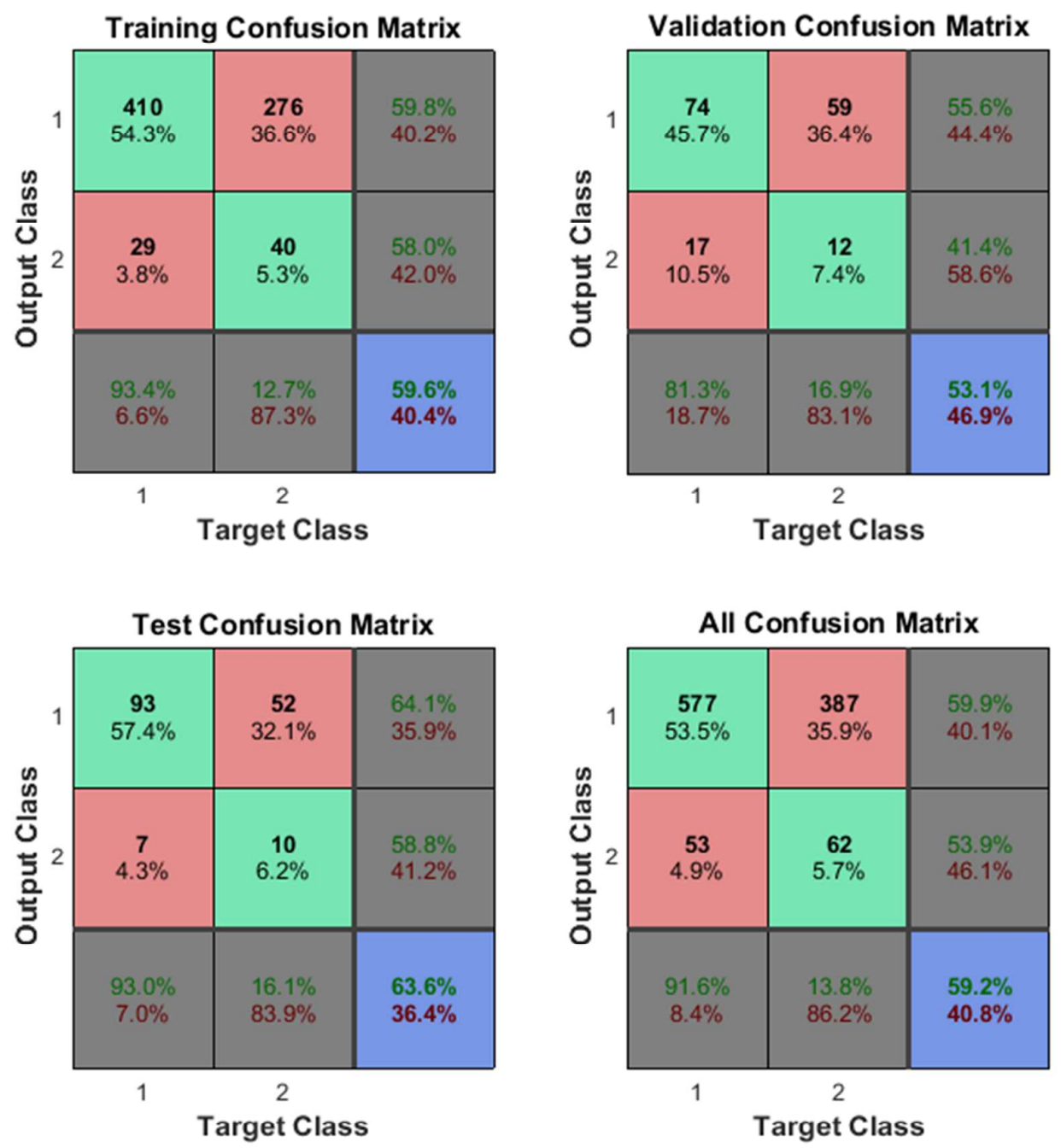

Figure 15: Confusion matrix for all patients using six-element features and all depths. Target Class 1 is PCa and Target Class 2 is benign.

http://mc.manuscriptcentral.com/(site) 

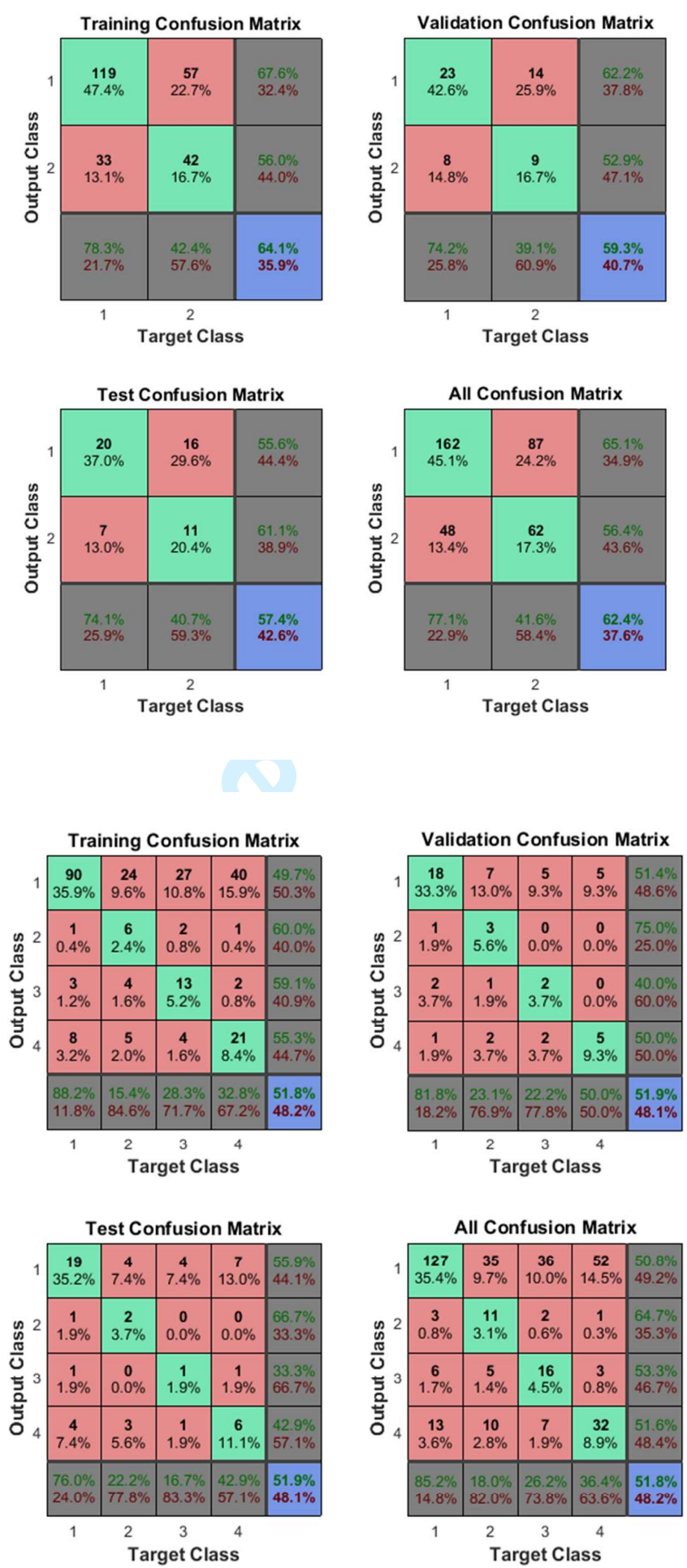

Figure 16: Confusion matrix for all patients using six-element features and all depths. Target Class 1 is PCa and Target Class 2 is benign for the 2-target matrix and, for the 4-target matrix, Class 1 is cancer, Class 2 is mixed, Class 3 is BPH and Class 4 is normal. 
Table 1: The number of measurement points recorded at $1 \mathrm{~Hz}$ and $5 \mathrm{~Hz}$ actuation frequencies and three depths for each tissue type identified in the 11 prostates measured.

\begin{tabular}{|l|l|l|c|}
\hline Tissue histological classification & $\mathbf{N}_{\mathbf{4 T}}$ & Simplified classification & $\mathbf{N}_{\mathbf{2}}$ \\
\hline Normal & 83 & Benign & 149 \\
\hline BPH & 66 & & \\
\hline Cancer & 149 & Cancer & 210 \\
\cline { 1 - 2 } Cancer and BPH & 61 & & 359 \\
\hline Total & \multicolumn{3}{|r}{} \\
\hline
\end{tabular}

Table 2: Statistical analysis of quasi-static modulus, dynamic modulus and phase difference for 11 prostates assessed with a mean depth of $3 \mathrm{~mm}$ (Figure 12).

\begin{tabular}{|c|c|c|c|c|c|c|}
\hline & $\begin{array}{l}\text { Normal } \\
(n=83)\end{array}$ & $\begin{array}{l}\text { Cancer } \\
(n=149)\end{array}$ & P-value & $\begin{array}{l}\text { Benign } \\
(n=149)\end{array}$ & $\begin{array}{l}\text { Malignant } \\
(\mathrm{n}=210)\end{array}$ & P-value \\
\hline$E_{\text {static }} 1 \mathrm{~Hz}(\mathrm{kPa})$ & $15.1 \pm 0.1$ & $15.1 \pm 0.2$ & 0.7 & $15.1 \pm 0.2$ & $15.1 \pm 0.2$ & 0.7 \\
\hline$E_{\text {dynamic }} 1 \mathrm{~Hz}(\mathrm{kPa})$ & $20.7 \pm 0.5$ & $20.8 \pm 0.6$ & 0.07 & $20.7 \pm 0.7$ & $20.8 \pm 0.7$ & 0.5 \\
\hline PD 1Hz (rad) & $-0.57 \pm 0.03$ & $-0.58 \pm 0.03$ & 0.003 & $0.57 \pm 0.04$ & $0.59 \pm 0.03$ & 0.002 \\
\hline$E_{\text {static }} 5 \mathrm{~Hz}(\mathrm{kPa})$ & $14.2 \pm 0.2$ & $14.4 \pm 0.2$ & $5 \times 10^{-7}$ & $14.3 \pm 0.2$ & $14.4 \pm 0.2$ & 0.0004 \\
\hline$E_{\text {dynamic }} 5 \mathrm{~Hz}(\mathrm{kPa})$ & $14.0 \pm 0.6$ & $14.3 \pm 0.8$ & 0.005 & $14.1 \pm 1.0$ & $14.3 \pm 0.8$ & 0.13 \\
\hline PD 5Hz (rad) & $1.19 \pm 0.15$ & $1.14 \pm 0.14$ & 0.04 & $1.18 \pm 0.15$ & $1.14 \pm 0.14$ & 0.007 \\
\hline
\end{tabular}

Table 3: Sensitivity analysis of ANN performance for P21 (Figure 13).

\begin{tabular}{|c|c|c|c|}
\hline \multirow[t]{2}{*}{ Points } & \multirow[t]{2}{*}{ Feature vector } & \multicolumn{2}{|c|}{$\begin{array}{l}\text { Percentage correct } \\
\text { classifications }\end{array}$} \\
\hline & & Test set & All \\
\hline All (1-35) & $\begin{array}{l}\text { All mech. features at each depth } \\
3 \times 35 \times 6\end{array}$ & 50 & 65.7 \\
\hline 1 to 28 & $\begin{array}{l}\text { All mech. features at each depth } \\
3 \times 28 \times 6\end{array}$ & 53.8 & 73.8 \\
\hline All & $\begin{array}{l}\text { Modulus only at each depth } \\
3 \times 35 \times 4\end{array}$ & 56.3 & 50.5 \\
\hline All & Dyn Modulus only at each depth & 68.8 & 64.8 \\
\hline
\end{tabular}

http://mc.manuscriptcentral.com/(site) 


\begin{tabular}{|l|l|l|l|}
\hline & $3 \times 35 \times 2$ & & \\
\hline All & Dyn Modulus and phase only at each depth $3 \times 35 \times 4$ & 56.3 & 69.5 \\
\hline All & $5 \mathrm{~Hz}$ only at each depth $3 \times 35 \times 3$ & 68.8 & 57.1 \\
\hline
\end{tabular}

Table 4: Sensitivity and specificity for all 11 patients using "All" confusion matrix.

\begin{tabular}{|c|c|c|c|}
\hline \multirow[t]{2}{*}{ Target } & \multirow[t]{2}{*}{ Feature vector } & \multicolumn{2}{|c|}{$\begin{array}{l}\text { Percentage correct } \\
\text { classifications }\end{array}$} \\
\hline & & Sensitivity & Specificity \\
\hline $\begin{array}{l}\text { Cancer } \\
\text { and } \\
\text { Benign }\end{array}$ & $\begin{array}{l}\text { All mech. features at each depth } \\
3 \times 35 \times 6 \text { (P21 only) }\end{array}$ & 68 & 63 \\
\hline $\begin{array}{l}\text { Cancer } \\
\text { and } \\
\text { Benign }\end{array}$ & $\begin{array}{l}\text { All mech. features at each depth } \\
3 \times 359 \times 6\end{array}$ & 60 & 54 \\
\hline $\begin{array}{l}\text { Cancer } \\
\text { and } \\
\text { Benign }\end{array}$ & $\begin{array}{l}\text { All mech. features at all depths } \\
359 \times 18\end{array}$ & 65 & 56 \\
\hline $\begin{array}{l}\text { Cancer } \\
\text { and } \\
\text { Benign }\end{array}$ & $\begin{array}{l}\text { All mech. features (ex. } E_{\text {static }} \text { ) at all depths } \\
359 \times 12\end{array}$ & 67 & 63 \\
\hline $\begin{array}{l}\text { Cancer } \\
\text { and } \\
\text { Benign }\end{array}$ & $\begin{array}{l}\text { All mech. features (ex. } E_{\text {static }} \text { ) at each depth (P21 only) } \\
3 \times 35 \times 4\end{array}$ & 78 & 76 \\
\hline $\begin{array}{l}\text { Cancer, } \\
\text { Mixed, } \\
\text { BPH and } \\
\text { Normal }\end{array}$ & $\begin{array}{l}\text { All mech. features at all depths } \\
359 \times 18\end{array}$ & $\begin{array}{l}52 \text { (any } \\
\text { disease) } \\
52 \text { (cancer) }\end{array}$ & 52 \\
\hline $\begin{array}{l}\text { Cancer } \\
\text { and } \\
\text { Normal }\end{array}$ & $\begin{array}{l}\text { All mech. features at all depths } \\
232 \times 18\end{array}$ & 73 & 62 \\
\hline $\begin{array}{l}\text { Cancer } \\
\text { and } \\
\text { Normal }\end{array}$ & $\begin{array}{l}\text { All mech. features (ex. } E_{\text {static }} \text { ) at all depths } \\
232 \times 12\end{array}$ & 73 & 62 \\
\hline
\end{tabular}


Table 5: Summary of published values of prostate elastic modulus

\begin{tabular}{|c|c|c|c|c|}
\hline Authors & Sample type & Test method & Notes & Modulus value(s) \\
\hline $\begin{array}{l}\text { Parker et al. } \\
\text { (39) }\end{array}$ & Whole prostates & $\begin{array}{l}\text { Ultrasonic resonance (3- } \\
7 \mathrm{MHz})\end{array}$ & Normal tissue only, linear elastic modulus & $2.15 \mathrm{kPa}$ \\
\hline $\begin{array}{l}\text { Krouskop et } \\
\text { al. (40) }\end{array}$ & "Small pieces" & $\begin{array}{l}\text { Sinusoidal indentation } \\
(4.83 \mathrm{~mm} \text { dia.) }, 0.1,1,4 \mathrm{~Hz} \text {, } \\
2 \% \text { and } 4 \% \text { pre-strain }\end{array}$ & $\begin{array}{l}\text { Normal, BPH and PCa. No phase difference } \\
\text { observed so only modulus reported. }\end{array}$ & $\begin{array}{l}\text { 40-85kPa normal, 30-55 BPH, } \\
75-270 \mathrm{PCa}\end{array}$ \\
\hline $\begin{array}{l}\text { Phipps et al. } \\
\text { (41) }\end{array}$ & TURP chips & $\begin{array}{l}\text { Sinusoidal indentation } \\
(2 \mathrm{~mm} \text { dia.), } 1-50 \mathrm{~Hz}, 20 \% \\
\text { mean strain }\end{array}$ & Dynamic modulus & $20-160 \mathrm{kPa}$ \\
\hline $\begin{array}{l}\text { Phipps et al. } \\
\text { (26) }\end{array}$ & TURP chips & $\begin{array}{l}\text { Sinusoidal indentation } \\
(2 \mathrm{~mm} \text { dia.), } 1-50 \mathrm{~Hz}, 20 \% \\
\text { mean strain }\end{array}$ & BPH vs PCa, Dynamic modulus and tan(PD) & $\begin{array}{l}\text { 100, } 0.22(\mathrm{BPH}), 110,0.15 \\
\text { (PCa) }\end{array}$ \\
\hline $\begin{array}{l}\text { Yang et al. } \\
(25)\end{array}$ & $\begin{array}{l}\text { Transverse slices, } 6 \mathrm{~mm} \\
\text { thick }\end{array}$ & $\begin{array}{l}\text { Sinusoidal indentation } \\
(2 \mathrm{~mm} \text { dia.) }, 5-30 \mathrm{~Hz}, 20 \% \\
\text { mean strain }\end{array}$ & $\begin{array}{l}\text { Dynamic modulus and tan(PD), variation with } \\
\text { frequency. No cancer present in samples. }\end{array}$ & $100-450 \mathrm{kPa}, 0-0.3$ \\
\hline $\begin{array}{l}\text { Zhang et al } \\
(42)\end{array}$ & $\begin{array}{l}\text { Cores } 8 \mathrm{~mm} \text { diameter and } \\
7 \mathrm{~mm} \text { long }\end{array}$ & $\begin{array}{l}\text { Stress relaxation at } 5 \% \\
\text { compressive strain. }\end{array}$ & $\begin{array}{l}\text { Results over 700s fitted to viscoelastic model } \\
\text { and extrapolated dynamic modulus and } \\
\tan (\mathrm{PD}) \text { to } 150 \mathrm{~Hz} \text {. Normal vs PCa. }\end{array}$ & $\begin{array}{l}\text { 10-22kPa, 0.3-0.4 (normal, 24- } \\
56,0.3-0.4 \text { (PCa) }\end{array}$ \\
\hline $\begin{array}{l}\text { Murayama } \\
\text { et al ( } 43)\end{array}$ & $\begin{array}{l}\text { Sections } 300 \text { micron } \\
\text { thick, obtained from } \\
\text { cores } 7 \mathrm{~mm} \text { dia and } \\
10 \mathrm{~mm} \text { long }\end{array}$ & $\begin{array}{l}\text { Microscale sensor (10 } \\
\text { micron dia.), resonant at } \\
89 \mathrm{kHz}\end{array}$ & $\begin{array}{l}\text { Modulus (E) calculated from frequency shift. } \\
42 \mathrm{k} \text { points probed on "normal" core from one } \\
\text { patient and 55k points from patient with PCa } \\
\text { used to give elasticity distribution }\end{array}$ & $\begin{array}{l}\text { Mode around } 10 \mathrm{kPa} \text { for } \\
\text { normal and PCa. Wider } \\
\text { distribution for PCa }\end{array}$ \\
\hline $\begin{array}{l}\text { Carson et al. } \\
(44)\end{array}$ & $\begin{array}{l}\text { Whole prostates and } \\
\text { some } 5-10 \mathrm{~mm} \text { thick } \\
\text { slices thereof }\end{array}$ & $\begin{array}{l}\text { Load-unload indentation to } \\
\text { around } 30 \% \text { strain over } \\
\text { several minutes. }\end{array}$ & $\begin{array}{l}\text { Young's modulus calculated from Oliver-Pharr } \\
\text { stiffness. Focus on prostates with palpable } \\
\text { abnormalities. }\end{array}$ & $\begin{array}{l}46.5 \pm 22.2 \text { palpable and } \\
31 \pm 63.1 \text { non palpable }\end{array}$ \\
\hline $\begin{array}{l}\text { Ahn and Kim } \\
\text { (45) }\end{array}$ & Whole prostates & $\begin{array}{l}2 \mathrm{~mm} \text { diameter } \\
\text { hemispherical indenter }\end{array}$ & Indentation from 0 to $3 \mathrm{~mm}$ at $1 \mathrm{~mm} / \mathrm{s}$ & $\begin{array}{l}15.2 \pm 5.8 \mathrm{kPa} \text { (normal), } 28.8 \pm \\
11.2 \mathrm{kPa} \text { (cancer) }\end{array}$ \\
\hline
\end{tabular}




\begin{tabular}{|c|c|c|c|c|}
\hline $\begin{array}{l}\text { Yang et al } \\
\text { (27) }\end{array}$ & $\begin{array}{l}\text { Transverse slices, } 6 \mathrm{~mm} \\
\text { thick }\end{array}$ & $\begin{array}{l}\text { Sinusoidal indentation } \\
(2 \mathrm{~mm} \text { dia.), } 5-30 \mathrm{~Hz}, 20 \% \\
\text { mean strain }\end{array}$ & $\begin{array}{l}\text { Quasi-static modulus. Dynamic modulus and } \\
\tan (\mathrm{PD}) \text {, variation with frequency. Nodular vs } \\
\text { stromal histological components in normal or } \\
\text { BPH prostates. }\end{array}$ & $\begin{array}{l}292 \mathrm{kPa}, 141-420 \mathrm{kPa}, 0.28-0.41 \\
\text { (nodular), } 325 \mathrm{kPa}, 115-236 \mathrm{kPa} \text {, } \\
0.31-0.45 \text { (stromal) }\end{array}$ \\
\hline $\begin{array}{l}\text { Yang et al } \\
\text { (27) }\end{array}$ & TURP chips & $\begin{array}{l}\text { Sinusoidal indentation } \\
(2 \mathrm{~mm} \text { dia.), } 5 \mathrm{~Hz}, 20 \% \text { mean } \\
\text { strain }\end{array}$ & $\begin{array}{l}\text { Quasi-static modulus. Dynamic modulus and } \\
\tan (\mathrm{PD}) \text {. Patients with BPH, some with PCa. }\end{array}$ & $\begin{array}{l}21 \mathrm{kPa}, 83 \mathrm{kPa}, 0.22(\mathrm{BPH}) \\
40 \mathrm{kPa}, 111 \mathrm{kPa}, 0.19(\mathrm{PCa})\end{array}$ \\
\hline This work & Whole prostates & $\begin{array}{l}\text { Sinusoidal indentation } \\
(4 \mathrm{~mm} \text { dia.), } 1 \mathrm{~Hz}, 5 \mathrm{~Hz} \text {, light, } \\
\text { medium, heavy mean } \\
\text { strain }\end{array}$ & $\begin{array}{l}\text { Quasi-static modulus. Dynamic modulus and } \\
\text { tan(PD). Probe points classified as Normal, } \\
\text { BPH, mixed and PCa. }\end{array}$ & $\begin{array}{l}\text { Typically } 15 \pm 0.5 \mathrm{kPa}, \\
20 \pm 0.5 \mathrm{kPa},-0.6 \pm 0.03 \mathrm{rad}(1 \mathrm{~Hz}), \\
1.2 \pm 0.1 \mathrm{rad}(5 \mathrm{~Hz})\end{array}$ \\
\hline
\end{tabular}




\section{Page 41 of 40}

Journal name

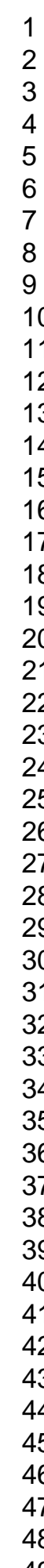

http://mc.manuscriptcentral.com/(site) 